\title{
SEGUNDO ARTÍCULO
}

"Falencias en el control administrativo respecto de la labor de control $y$ vigilancia de los contratos estatales"

\section{Tabla de contenido}

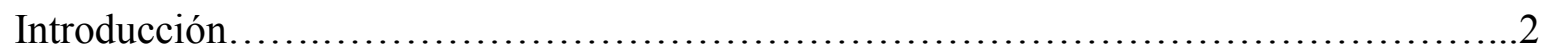

1. Exposición de motivos y disposiciones legales.................................. 4

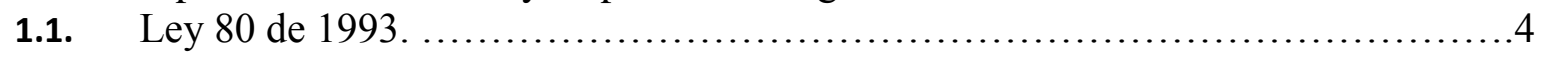

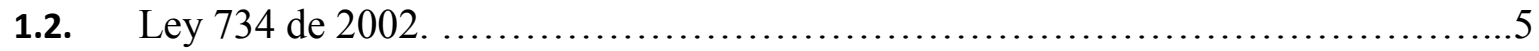

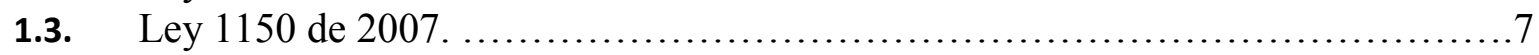

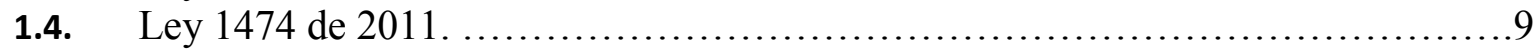

1.5. Esquema Dogmático y exposición de motivos de la contratación estatal e interventoría en Colombia.....................................................13

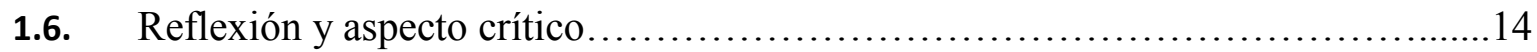

2. Teoría Económica (internacional - colombiana)............................. 15

3. La interventoría como delegación del Estado................................18

4. Precedente judicial, Consejo de Estado. Interventoría- interventoría externa.........22

5. Control y vigilancia disciplinaria (Precedente Constitucional) .....................37

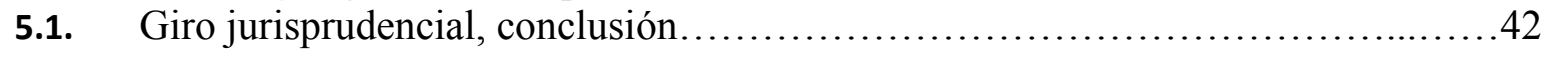

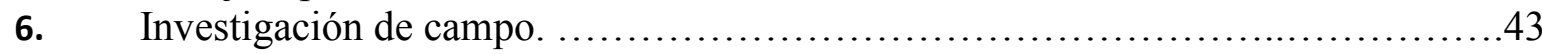

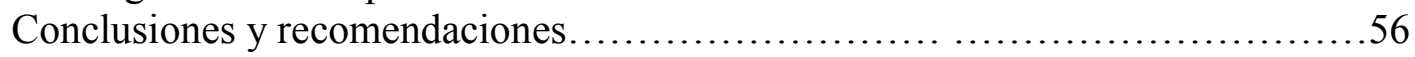

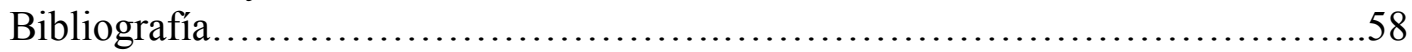

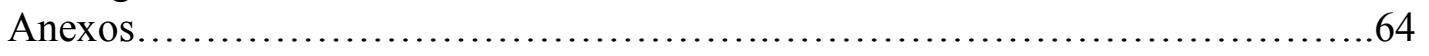




\section{INTRODUCCIÓN}

El presente trabajo abarcara como problema jurídico central, las falencias en el control administrativo respecto de la labor de control y vigilancia de los contratos estatales. Para ello, se mostrara el querer inicial del legislador en las diferentes exposiciones normativas desarrolladas en orden cronológico, un precedente judicial expuesto en el Consejo de Estado desde el año de 1991 hasta 2010 y un importante precedente constitucional en lo coherente al control y vigilancia disciplinaria de las firmas o empresas interventoras.

La contratación de interventores está ligada a la adecuada administración del patrimonio estatal y éste se constituye en garantía de legalidad mediante un adecuado seguimiento y autorización de operaciones para el desarrollo contractual. Al interventor se le conceden determinadas facultades cuyo ejercicio denota responsabilidades de tipo administrativo, financiero, técnico y legal. La interventoría debe verificar el control de las actividades previstas inclusive desde que se determina la necesidad de la contratación. De ahí que su objetivo sea garantizar que la legalidad que orientó el proceso contractual, esté acorde con la ejecución del contrato, contribuyendo con los objetivos de la entidad estatal para la adecuada retribución de los recursos, garantizando que éstos se ejecuten con criterios de eficacia, eficiencia y con el cumplimiento de la normatividad vigente.

Al identificar las posibles falencias en el control administrativo de los interventores externos y su implicación dentro del buen funcionamiento de las entidades públicas, es posible prever una adecuada ejecución contractual, así como el logro de los resultados esperados (el mercado como forma de control), para lo cual es necesario desde un primer momento, que la contratación de interventores externos apunte a cumplir los proyectos establecidos desde el plan de compras, indagando cuándo legalmente un proyecto requiere de un interventor externo o cuándo esta labor puede ser desarrollada por un supervisor interno, como puntualmente lo señala el Estatuto Anticorrupción (2011, Ley 1474).

Actualmente, en el contexto colombiano, los estudios realizados sobre este tema, se caracterizan por su escasez y poca profundidad interdisciplinaria, como quiera que se persiste en abordarlos desde un enfoque puramente jurídico sin considerar que la problemática desprendida de las falencias propias del ejercicio del control y supervisión contractual de los interventores demanda un esfuerzo mucho más integral y de colaboración que involucra tantas disciplinas como ciencias se requieran, cada una de ellas haciendo sus respectivos aportes a partir de sus propias concepciones y metodologías. 
1. Exposición de motivos y disposiciones legales. 
Para desarrollar el tema objeto de estudio, resulta imprescindible en primer término, hacer una descripción cronológica de la exposición de motivos que conllevaron a la expedición de las principales normas que regulan lo atinente al ejercicio de la interventoría en Colombia, es así como se describirá el espíritu del legislador y cuales han sido los grandes giros que se han dado en el aspecto de la contratación pública especialmente en lo pertinente a interventoría.

\subsection{Ley 80 de 1993}

Basta aclarar que el Estatuto de Contratación Estatal, surge como una necesidad de luchar por la recta eficacia en la administración de los recursos destinados a los contratos estatales, como lo es por ejemplo la ejecución de una u otra obra pública.

En seguida nos dedicaremos a estudiar algunos artículos y disposiciones del proyecto de ley del estatuto ya mencionado.

En materia de lucha contra la corrupción, el artículo $1^{\circ}$ del proyecto de ley proponía de una parte, que "los contratos derivados de la celebración de contratos o convenios interadministrativos y ejecutados por las administraciones públicas cooperativas y asociaciones conformadas por entidades territoriales se rijan por lo dispuesto en la Ley 80 (exposición de motivos, 1993)", con el fin de acabar con la práctica de estas entidades que valiéndose de las ventajas que comporta para la selección y entrega de recursos por vía de los llamados convenios interadministrativos y a pesar de no contar con la idoneidad y experiencia requerida para la ejecución de contratos, se venían convirtiendo en los grandes contratistas del Estado, en especial a nivel territorial. La entrega de recursos sin ningún tipo de control o auditoria para su manejo a este tipo de entes se ha convertido en un semillero para la corrupción promovido tanto por las entidades contratantes como por la respectiva asociación, lo que genera la desviación de importantes recursos con los costos sociales y económicos que ello implica.

Por otra parte, y buscando la transparencia en la asignación y entrega de recursos públicos por vía de contratos, el artículo $2^{\circ}$ del proyecto tiene por objeto restringir la normativa para la ejecución de los contratos financiados con fondos de los organismos multilaterales de crédito y para los contratos celebrados con personas jurídicas de derecho público 
internacional u organismos de cooperación, asistencia o ayuda internacional, en el sentido de que la excepción esté construida alrededor del objeto y no del sujeto, en consecuencia se propone que ésta sea aplicada para los contratos financiados con recursos de banca multilateral, con recursos provenientes de cooperación internacional o derivados de créditos concesionales.

En consonancia con la motivación del proyecto de ley de generar escenarios de transparencia y dotar a las entidades de instrumentos para la eficiencia en su contratación, en el artículo $9^{\circ}$ del proyecto de ley se proponía un nuevo entendimiento para el registro de proponentes.

Otra de las grandes innovaciones propuestas alrededor del principio de la transparencia, está señalada en el artículo 14 del proyecto de ley que propendía por el fomento a la "utilización y creación de mecanismos e instrumentos legales para la administración y enajenación de los bienes del Estado en la búsqueda de que éste, al igual que los particulares pueda percibir rentabilidad de sus bienes y productos" (exposición de motivos ley 80, 1993), para lo cual se difiere al Gobierno Nacional el señalamiento de las pautas y condiciones para la utilización de esta clase de instrumentos.

\subsection{Ley 734 de 2002}

Ahora, hablaremos del Código Disciplinario Único (ley 734 articulo 53, 2002) en lo relacionado con temas contractuales públicos, en especial de la interventoría. Especificaremos el querer e impulso del legislador, en especial del senado, con el proyecto de ley numero 19 (año 2000) hasta llegar al año 2002, y así, llegar a la expedición de ésta legislación que trajo varios cambios en la forma de ver la contratación estatal interventoría- desde el ámbito disciplinario.

En el proyecto de ley ya mencionado, se tenía en el artículo 61 numeral séptimo como sujetos disciplinables a los "interventores de los contratos estatales" (Proyecto de Ley número 19 Artículo 61, 2000). 
Ya cuando quedo finalizado el proyecto de ley y se publicó en las gacetas del Congreso de la Republica, el nuevo texto (artículo 53) en lo referente a la labor de interventoría, dispuso: "El presente régimen se aplica a los particulares que cumplan labores de interventoría o supervisión en los contratos estatales..." (Ley 734, 2002).

En lo referente a principios básicos en materia de contratación pública, la expedición de esta ley tuvo los siguientes motivos o fundamentos:

En materia de contratación estatal también se advierte que la gestión de control de la Procuraduría no resulta eficiente debido a que la enumeración taxativa de las faltas gravísimas no incluyó aquellos comportamientos que desconocen de manera más severa los principios y normas básicas que regulan la contratación del Estado.

La corrupción administrativa en esta materia ha aumentado, lo cual se evidencia con las frecuentes y masivas denuncias contra los organismos del Estado, por la celebración de contratos millonarios que no tienen una justificación legal y persiguen cometidos diferentes a los previstos en la Constitución y la ley.

En este campo es frecuente que los representantes de las entidades públicas celebren contratos con personas inhabilitadas, para pagar favores políticos o de cualquier otra índole. También es frecuente que se omitan los estudios técnicos, financieros y jurídicos requeridos para garantizar la calidad de las obras, y se adjudiquen los contratos por razones de favoritismo. Igualmente, se ha hecho evidente que los servidores públicos recurren a la actividad contractual para obtener provecho ilícito en detrimento del patrimonio público (exposición de motivos ley 734, 2002).

Siguiendo con el aspecto de la corrupción, en la citada exposición de motivos (ley 734 2002), se agrega:

La corrupción en materia contractual también se genera con la declaratoria de caducidad o con la terminación de los contratos sin que se reúnan las causales que la ley ha previsto para ello, con el fin de asignar dichos contratos a las personas con quienes se han adquirido compromisos que no pueden cumplirse debido a que los recursos presupuestales ya han sido comprometidos por administraciones anteriores. Dichas declaratorias de caducidad generan demandas contra el Estado, que prosperan en la mayoría de los casos, con lo cual se afecta el patrimonio público, además de la ejecución del contrato.

Como puede apreciarse, continúa con plena vigencia lo querido por el legislador al expedir la Ley 80 de 1993, ya que debe propenderse por la selección de contratistas del Estado 
acorde con principios de selección objetiva (transparencia), planeación, responsabilidad, entre otros, con el fin de que así mismo se garantice una adecuada y eficiente ejecución contractual, para lo cual, sin lugar a dudas es importantísima la labor de seguimiento y control que se encuentra en cabeza de los interventores contratados o designados para tal efecto.

Nos referiremos ahora al tema de la interventoría y señalaremos el espíritu del legislador en aquella ocasión:

Los interventores no exigen el cumplimiento de las especificaciones técnicas durante la ejecución del contrato o permiten que se entreguen obras inconclusas, de mala calidad o diferentes de las pactadas, con el fin de obtener prebendas del contratista o la ampliación de sus contratos por parte de la entidad, aumentando así sus ingresos indebidamente y afectando la calidad de las obras y la correcta prestación de los servicios contratados por la entidad estatal. (Exposición de motivos ley 734, 2002).

En lo relacionado con este tema, podemos ver las falencias que existen en un aspecto tan preponderante para poder ejecutar de una manera recta y transparente una obra pública, como lo es el contrato de interventoría, esta omisión genera mayores costos y demoras injustificadas en la entrega de bienes, obras y/o servicios.

\subsection{Ley 1150 de 2007}

Siguiendo el orden cronológico, nos encontramos con esta importante ley, que modifica varias disposiciones de la Ley 80 de 1993, y que en concepto del legislador, están relacionadas con los vacíos, principalmente en lo relacionado con el gasto público, cuando la falta de control genera la indebida ejecución de recursos.

Por lo anterior el espíritu del legislador en el año 2007, señaló:

En cuanto constituye el principal instrumento de ejecución del gasto público, la contratación pública aparece como un asunto esencial para el correcto devenir de la administración pública y, por ende, para la satisfacción de los cometidos estatales. 
Adicionalmente, por el tamaño de la misma, es sin duda también la contratación pública un instrumento de singular valía dentro del entorno de la materialización de los objetivos socio-económicos de la administración. Un simple dato resulta explícito: La participación promedio de la contratación del sector público en el PIB supera el 11\%, lo que debe llevar a concluir que cualquier medida que impacte tal volumen de recursos, sin duda tendrá una significación mayor en el contexto no sólo de la administración pública, sino en el terreno de lo económico.

Aquí encontramos que cualquier defraudación al patrimonio estatal, tiene repercusiones en todo el campo económico del territorio nacional, por lo cual resulta necesario insistir en la estricta aplicación de la normatividad contractual tanto a los funcionarios públicos, a los contratistas e interventores como colaboradores de la administración.

Por otro lado, el proyecto se esmera en restringir prácticas abusivas o ilegales que afecten la sana competencia e igualdad de oportunidades de los proponentes en los procesos contractuales. De esta forma, regula los requisitos mínimos para participar en los procesos de selección, permitiendo subsanar errores meramente formales que no alteren las condiciones sustanciales de las ofertas, etc.

En lo pertinente a la licitación pública, el querer del proyecto de ley (2007) fue:

La Licitación Pública sigue siendo la regla general, la misma pasa a reservarse para los procesos en los que la complejidad del objeto a contratar amerita la larga y cuidadosa ponderación de factores técnicos y económicos de las propuestas. El proyecto prevé en cualquier caso, la posibilidad de hacer uso de mecanismos de subasta para la conformación de la oferta de los proponentes, superando las limitaciones de los sistemas de "sobre cerrado" y "extrayendo valor" para la entidad contratante, fruto de la exposición al mercado de las posturas de los interesados.

Concluye diciendo:

El proyecto de ley que hoy se presenta no tiene por objeto dictar un nuevo estatuto general de contratación, sino introducir medidas puntuales que permitan a las entidades 
hacer más eficiente y transparente su gestión, así como corregir algunas fallas que se han presentado en su aplicación y que han derivado en espacios que son aprovechados por la corrupción para desviar los recursos de las finalidades estatales a los que se encuentran destinados. De igual manera se propone la adopción de medidas legislativas que, aplicables a toda contratación efectuada con recursos públicos con independencia de su régimen legal, aseguren la vigencia uniforme de los principios constitucionales de la función pública y del régimen legal de inhabilidades e incompatibilidades. En puntos tan cardinales, no puede haber excepción alguna. (Exposición de motivos ley 1150, 2007).

Como podemos observar, se enfatiza en la aplicación de principios de eficiencia y trasparencia en la gestión de los contratos estatales, adoptando medidas legislativas para la correcta destinación de los recursos públicos.

\subsection{Ley 1474 de 2011}

Es del caso señalar, que el proyecto de ley del Estatuto Anticorrupción fue el número 142 del año 2010, impulsado por el Senado de la República.

En el séptimo capítulo del proyecto ya mencionado, se establecieron las "disposiciones para prevenir y combatir la corrupción en la contratación pública”.

El legislador en aquella ocasión puntualizó sobre el particular:

La contratación pública es el sector en el cual se vienen presentando los casos más graves de corrupción pública; por ello es necesario realizar formas puntuales para aumentar la trasparencia y garantizar la sanción, evitar la corrupción y el fraude en esta actividad estatal.

Hay un gran vacío en la normatividad para la vigilancia contractual, razón por la cual a través de este proyecto se fortalece el sistema de interventoría. Se carece de un referente legal en materia de supervisión e interventoria de la actividad contractual, que se ha traducido en debilidades en el control y seguimiento del Estado sobre la ejecución contractual. 
En ese sentido y con el propósito de contar con un sistema efectivo de control de la administración sobre la ejecución de los contratos estatales, el proyecto dispone:

Que es mandatorio que los contratos estatales cuenten con supervisión o interventoría, de suerte que siempre se vigile su ejecución.

Todo contrato de obra pública de mayor cuantía deberá contar con interventoria, y se obliga a que en los demás que superen este valor, los estudios previos se pronuncien sobre la pertinencia de contar con la misma.

Se aclara el alcance de los deberes de supervisores e interventores, y se les hace responsable de poner en conocimiento de la entidad contratante los posibles actos de corrupción, así como de alertar oportunamente sobre posibles incumplimientos.

La interventoría debe ser continua. Si la obra se alarga, la interventoría también. No tiene sentido que, a la mitad de la obra, se la deba detener mientras se contrata una nueva interventoría (Proyecto de Ley número 142, 2010).

En los anteriores puntos, es claro y evidente el impulso del legislador al querer darle un giro al ámbito de la interventoría estatal, siendo así, más riguroso que en los motivos ya expuestos que los llevaron a impulsar las leyes anteriores.

En materia de responsabilidad, más adelante agrega:

$(\ldots)$

La falta de información oportuna de la entidad por parte de los supervisores e interventores los hará solidariamente responsables con el contratista por los perjuicios causados, amén de las responsabilidades personales que se generen en materia disciplinaria para los servidores y de inhabilitación para los interventores (Ibídem. proyecto de ley No. 142, 2010).

Se observa cómo aparece de bulto el tema de la responsabilidad en cabeza de los particulares que ejercen funciones públicas, estableciendo sanciones por la falencia en el ejercicio de las actividades de control y vigilancia para el caso de los interventores como colaboradores del Estado. Las clases de responsabilidades en este referente, la encontramos de una manera más amplia en el primer artículo de nuestro trabajo denominado: “"Responsabilidad de los interventores externos en el Ámbito de la Contratación Estatal". 
Terminando con el análisis de la exposición de motivos de ésta importante ley en materia de corrupción, basta mencionar las disposiciones legales contenidas en el proyecto de ley 142 del año 2010 y en el proyecto final, ley 1474 de 2011.

En el artículo 77 del proyecto de ley número 142 se hablaba de la responsabilidad de los interventores, el que comparado con el artículo 82 de la ley 1474 de 2011, ofrece una lectura exacta y por ende un contenido idéntico en los dos primeros incisos, señalando lo siguiente:

Artículo 82. Responsabilidad de los interventores.

Los consultores y asesores externos responderán civil, fiscal, penal y disciplinariamente tanto por el cumplimiento de las obligaciones derivadas del contrato de consultoría o asesoría, como por los hechos u omisiones que les fueren imputables y que causen daño o perjuicio a las entidades, derivados de la celebración y ejecución de los contratos respecto de los cuales hayan ejercido o ejerzan las actividades de consultoría o asesoría.

Por su parte, los interventores responderán civil, fiscal, penal y disciplinariamente, tanto por el cumplimiento de las obligaciones derivadas del contrato de interventoría, como por los hechos u omisiones que les sean imputables y causen daño o perjuicio a las entidades, derivados de la celebración y ejecución de los contratos respecto de los cuales hayan ejercido o ejerzan las funciones de interventoría.

En el proyecto de ley (2010), existía un inciso adicional que contemplaba lo siguiente:

Los interventores y supervisores deberán publicar en la respectiva pagina web de la entidad, los informes de ejecución con sus respectivas actas, de los contratos o convenios puestos a su vigilancia y control, con la periodicidad que se establezcan en los mismos, el interventor o supervisor, junto con el representante legal de la entidad, serán los responsables de efectuar la publicación.

Como podemos ver en este último inciso, existía la pretensión de utilizar medios electrónicos para que la ciudadanía en general tuviera acceso a los informes y demás documentos relacionados con la ejecución del contrato, lo cual desafortunadamente no fue incluido en el texto final de la Ley 1474 de 2011. 
Es de resaltar que las demás disposiciones como lo son por ejemplo las contenidas en: el artículo 84 (facultades y deberes de los supervisores y los interventores), el artículo 85 (continuidad de la interventoría) donde el querer del legislador fue como ya lo mencionamos anteriormente, que la interventoría sea continúa y no quede restringida en la posibilidad de adicionarse en más de un 50\% de su valor inicial y por ende se garantice con ello la culminación acorde con el contrato vigilado. No tendría sentido que a la mitad de la obra, ésta se deba detener hasta conseguir una nueva firma interventora; disposiciones que se mantuvieron iguales en su esencia, pues lo único que cambio fue la redacción en los textos correspondientes.

1.5. ESQUEMA DOGMATICO Y EXPOSICION DE MOTIVOS

DE LA CONTRATACION ESTATAL E INTERVENTORIA EN COLOMBIA 


\subsection{Reflexión y aspecto crítico}

Pesé al esfuerzo del legislador para tipificar responsabilidades en cabeza de los particulares y en especial de los interventores como representantes de la entidad pública y responsables del control de ejecución de los contratos estatales, en la actualidad vemos que aún no se logran los cometidos esperados en materia de lucha contra la corrupción, a pesar de que se han venido desarrollado varias reformas legislativas y reglamentarias en torno al tema, lo que nos lleva a pensar es que en realidad el problema involucra varios actores y escenarios que van desde la formación de los gobernantes, funcionarios públicos y el oportunismo de los contratistas del estado.

Podemos preguntarnos: ¿en realidad es un problema de vacios en la ley?, o tal vez, ¿el tema está relacionado con las políticas públicas?, o más allá, sí en realidad ¿es un problema de cultura ciudadana?

Todo nos indica que la problemática central se enfoca en la cultura y desapego de lo público de la mayoría de los ciudadanos en nuestro país, pues no es coherente que exista multiplicidad de normatividad que propugne por la transparencia en la contratación estatal, y que no sea cumplida en muchos de los casos a causa de intereses personales, falta de planeación y ligereza en la toma de decisiones en materia contractual pública. 


\section{Teoría económica del control contractual (internacional - colombiana)}

Para autores como Manuel Jiménez Moriones, la interventoría es esencialmente una actividad de control y vigilancia de un contrato estatal, teniendo como propósito central el de verificar el cumplimiento integral de su objeto y de las obligaciones pactadas por las partes, sirviendo de mediador efectivo en aras de lograr la culminación (resultados) satisfactoria (en términos de calidad) del contrato.

En la práctica encontramos, que dicho propósito superior del interventor, no se alcanza a cumplir debido a múltiples dificultades que tienen que ver, en un principio, con la propia actitud del Estado que percibe la interventoría como un instrumento accesorio al contrato (generalmente de obra). De igual modo, algunas falencias que presenta el control y vigilancia de los interventores se asocia con la llamada urgencia social, política y económica de los proyectos y que obliga a las entidades públicas a contratar sin observar, con mayor atención y cuidados, tanto la naturaleza como los aspectos más formales de la contratación de obra y de interventoría.

No obstante, desde un enfoque económico de la interpretación de los problemas suscitados en la calidad del control y vigilancia, para los cuales es contratado por el Estado una firma interventora, cabe señalarse como hipótesis de trabajo: Que la interventoría no se traduce en un control completo y eficiente que garantice la calidad final de las obras y tampoco la no aparición de prácticas de corrupción, en tanto no se escoja de manera técnica y coherente el tipo de gobernación de la transacción.

Para autores como Per Erik Eriksson (Suecia, 2008), se establecen res tipos de gobernación de la transacción: 
1. El mercado

2. El híbrido

3. La jerarquía

La primera hace referencia a un bajo nivel de intensidad de control administrativo, correspondiendo más al control de los resultados (productos) que, conforme a la agencia, establece una relación entre la compensación y los resultados susceptible de medición, convertidos a una escala de valores numéricos, que permiten determinar que, pese a su débil control, la administración puede incrementar o disminuir su nivel de adquisiciones.

La segunda forma de gobernación alude a la calidad de inmediatez que debe revestir al control administrativo en relación con la intensidad de los incentivos, lo cual funciona mejor cuando se combina con formas de control social que se alcanza al disminuir notablemente la diferencia de preferencias entre el contratante y el contratista, lo cual incide en la función del interventor que va a encontrar una especie de alianza estratégica que le despojará de un alto nivel de tareas pero no así de responsabilidades.

Y, por último, la gobernación por jerarquía, refleja un alto grado o intensidad del control administrativo en contraste con los incentivos que se tornan mínimos, con una marcada tendencia a desaparecer. En este aspecto, Eriksson (2008 p. 103-111) señala que la jerarquía se interrelaciona satisfactoriamente con el control de procesos, que disminuye la participación, compromiso y confianza del contratista, pero que de manera inconveniente puede suscitar conductas proclives al oportunismo que pueden traducirse abiertamente en corrupción y reflejar, de paso, falta de control. Al respecto, los interventores estarían frente a situaciones de exigencia que, en la práctica, no siempre están dispuestos a cumplir dado que en la realidad socioeconómica de nuestro país se dan inversiones de roles: el interventor de hoy es el contratista de obra del mañana, y a la inversa, el contratista de hoy puede ser el interventor del mañana.

Cuando la gobernación escogida no logra satisfacer los requerimientos de la contratación, por la magnitud de la obra, por los imprevistos, por las condiciones ambientales complejas, por fisuras en la organización y en las comunicaciones de la administración, etc., nos enfrentamos a sensibles problemas para los que a la interventoría le es imposible armonizar y establecer equilibrios entre las partes contractuales, con objeto de garantizar los 
resultados exitosos de la obra misma. Y $\quad \mathrm{Y}$ desde aquí comienzan a identificarse otros problemas derivados, conexos y a observarse falencias que no podrían explicarse y entenderse por el sólo análisis jurídico de los fenómenos.

Al respecto, un estudioso del tema como Miguel Ángel Bautista (1998), ha detectado cómo los interventores se encuentran en una posición tal que les impide contar con la capacidad suficiente para ejercer controles al desarrollo de las obras: "El interventor apenas participa en la organización de su propio grupo de trabajo. Es natural que no pueda intervenir en la organización interna del contratista y, por otra parte, apenas se le ocurre informarse sobre la organización general de la entidad (contratante)". Situación que pone de relieve y compromete la calidad de la función de control por parte del interventor, sobre todo cuando el desacierto en la selección de la gobernación de la transacción se combina con la actitud estatal de concebir el contrato de interventoría como, no poco menos, que un simple apéndice del contrato de obra, lo que se refleja -en la práctica- en diversas falencias en la función del control y vigilancia tanto del interventor con respecto al contratista.

La Teoría Económica que hemos venido examinando, no es propensa a la figura de la delegación entre el Estado y el interventor, pero establece recomendaciones tanto administrativas como económicas que pueden mejorar sensiblemente el control y la vigilancia en la medida en que el Estado delegante no deje de controlar a quienes ha contratado para que ejerzan control y vigilancia. En este sentido, Miguel Ángel Bautista (1998, p.71) nos recuerda que: "La interventoría realiza labores de control que en ocasiones toman medidas de apremio pero éstas corresponden más a excepciones que a la regla. De ahí los atrasos, excesos en valores y sobrecostos sin previo aviso".

Como hemos podido examinar, las falencias en el control administrativo respecto de la labor de control y vigilancia de los interventores, a la luz de la Teoría Económica expuesta, deja al descubierto problemas cuyo origen primario se relacionan con el modelo de gobernación de la transacción escogido, con la falta de control administrativo en la delegación que el Estado extiende al interventor de sus funciones de control, con la idea de accesorio en que concibe la administración al contratista de interventoría y con la deficiente capacidad que otorgan los contratos públicos, lo cual impide optimizar la responsabilidad de los interventores, entre otros aspectos.

Esquematización de las conclusiones a las que llega el análisis de la Teoría Económica: 


\section{La interventoría como delegación del Estado.}

El tratadista Jaime Lemoine Gaitán (2010), respecto del fenómeno jurídico de la delegación estatal manifiesta:

No obstante la competencia asignada en el Estatuto de Contratación para celebrar contratos, el artículo 12 permite delegar dicha facultad en funcionarios del nivel directivo o ejecutivo o sus equivalentes.

También se puede efectuar delegación entre entidades del orden nacional y territorial, mediante la celebración de convenios interadministrativos.

La delegación puede ser total o parcial. En la primera, el delegatario asume la competencia de todo el trámite de celebración, ejecución y liquidación de los contratos. En la segunda, puede asumir el delegatario una parte de los trámites (precontractual) o la de algunos contratos hasta por determinada cuantía o según el tipo de contrato. Además se puede delegar la potestad de realizar el seguimiento y control a la ejecución de un contrato estatal.

En la contratación estatal y en aplicación de los principios contenidos en el estatuto contractual, les corresponde a los gerentes o directores, y en general a los representantes legales de la entidad, la función de ejercer el control y la vigilancia de la ejecución de los contratos celebrados por esta, en forma directa (interna) o mediante la celebración del contrato de interventoría (externa).

En efecto, la interventoría como función de control y vigilancia se delega en un funcionario de la entidad, mediante un acto administrativo se traslada a un consultor mediante un procedimiento de contratación- concurso de méritos que da lugar a la celebración de un contrato de consultoría denominado de interventoría. Por tanto, se puede afirmar que la interventoría interna es aquella cuya responsabilidad de ejercerla recae en una función de la entidad estatal contratante y que se materializa mediante un acto de delegación en el cual se fijan ámbito, alcance y funciones. En el acto de delegación el delegante se puede remitir a los llamados manuales de interventoría, o sea, aquellos actos administrativos de carácter general que se expiden con el fin de determinar las facultades y las funciones de los interventores.

El interventor designado debe contar con la experiencia y la idoneidad requerida, y deberá ser profesional en la especialidad que requiera el contrato.

\section{- Responsabilidad de los servidores públicos- delegante y delegatario}


Señala el artículo 211 de la Constitución Política (1991) que: "La delegación exime de responsabilidad al delegante, la cual corresponderá exclusivamente al delegatario", en principio, se podría afirmar que por el solo hecho de la delegación, el delegante quedaría eximido de toda responsabilidad frente a la ejecución de la función delegada.

No obstante, no es dable efectuar una interpretación literal y aislada de la norma citada y, por tanto, es necesario destacar la siguiente doctrina constitucional:

\section{- De la delegación en firma:}

Es importante señalar que la delegación, en principio, exime de responsabilidad al delegante, excepto cuando se delegue o autorice simplemente la suscripción por parte del delegatario del respectivo contrato.

En este caso el delegante es responsable del proceso de contratación y no puede utilizarse el mecanismo de la delegación para evadir las responsabilidades propias del cargo o empleo, en el cual no se ha trasladado ninguna competencia al delegatario por el solo hecho de la firma (Corte Constitucional - Sentencia C-727, 2000).

Complementando lo anterior, es del caso traer al estudio lo dispuesto en el estatuto de contratación pública (ley 800 de 1993) respecto al principio de responsabilidad contractual:

Artículo 26, numeral 5. La responsabilidad de la dirección y manejo de la actividad contractual y de los procesos de selección será del jefe o representante de la entidad estatal quien no podrá trasladar a las juntas o consejos directivos de la entidad, ni a las corporaciones de elección popular, a los comités asesores, ni a los organismos de control y vigilancia de la misma.

\section{- Acción de repetición y llamamiento en garantía}

En cuanto a la responsabilidad civil del delegante y del delegatario en materia contractual, en sentencia C-372, la Corte Constitucional (2002) señaló, con ocasión del examen de exequibilidad del artículo 2 de la Ley 678 de 2001 (mediante la cual se reglamentó la 
acción de repetición y el llamamiento en garantía) los criterios para determinar la responsabilidad de delegante y delegatario.

La Corte (2002) precisó que "no se puede dar al artículo 211 de la Constitución Política la interpretación de que por el solo hecho de la delegación, el delegante queda eximido de toda responsabilidad o que delegante y delegatario responden siempre por las decisiones que se tomen en la delegación conferida”.

Además estableció los siguientes criterios para determinar la responsabilidad de delegante y delegatario:

- El dolo la culpa grave corresponden exclusivamente al delegatario, al ejercer la delegación otorgada, sin la participación del delegante;

- El dolo o la culpa grave corresponden exclusivamente al delegante, quien utiliza al delegatario como un mero instrumento de conducta;

- Hay concurso de dolo y/o culpa grave de delegante y delegatario en la conducta que ocasiona el daño antijurídico.

Además expresó:

En suma, la expresión del artículo 211 dice que el delegante no responde por las actuaciones del delegatario, lo cual no significa que aquel no responda por sus propias acciones u omisiones en relación con los deberes de dirección, orientación, instrucción y seguimiento, las cuales serán fuente de responsabilidad cuando impliquen infracción a la constitución y a la ley, la omisión o extralimitación en el ejercicio de sus funciones o el cumplimiento de los principios de la función administrativa.

\section{- Aspectos referidos a Ley 1150 de 2007 en la delegación}

El artículo 21 de la ley 1150 (2007) recoge la doctrina constitucional antes mencionada y consagra que "En ningún caso, los jefes y representantes legales de las entidades estatales quedaran exonerados por virtud de la delegación de sus deberes de control y vigilancia de la actividad precontractual y contractual"

Por su parte, en sentencia más reciente, la Corte Constitucional declaró exequible la norma en comento y explicó lo siguiente: 
(...) Unánimemente estiman que una interpretación sistemática y armónica de todos los textos superiores lleva a concluir que existen otras normas constitucionales distintas del artículo 211 de la Carta, que le imponen al delegante obligaciones permanentes de vigilancia y control sobre la actividad del delegatario, y que impiden considerar a aquel desvinculado de toda responsabilidad por el solo hecho de la delegación. (Sentencia C693 de 2008).

En otro sentido, encontramos que "El interventor recibe una delegación legal del contratante y responde por la ejecución y seguimiento del contrato ante auditores, contralores, procuradores y gerentes de proyecto. Los interventores de obras civiles deben ser preferiblemente Ingenieros Civiles o Arquitectos y los Interventores de otras obras deben tener formación universitaria o tecnológica según la clase de Interventoría".

A continuación realizaremos un análisis a cerca de la evolución jurisprudencial que ha tenido el Consejo de Estado en nuestro país, desde el año de 1991 hasta el 2010 en lo relacionado con el tema "interventoría- interventoría externa". 


\section{Precedente Judicial, Consejo de Estado. Interventoría- interventoría externa.}

"La evolución de la interventoria - interventoria Externa en Colombia desde el punto de vista de la Jurisprudencia”.

A continuación realizaremos un análisis a cerca del avance a nivel jurisprudencial que ha tenido el Consejo de Estado en nuestro país, desde el año de 1991 hasta el 2010 en lo relacionado con el tema "interventoría- interventoría externa".

\begin{tabular}{|l|l|}
\hline Institución & Consejo de Estado \\
\hline No. Expediente & 1991-N5127 \\
\hline Sala & Sección Tercera \\
\hline
\end{tabular}

\section{Problema jurídico:}

En este primer avance, se señaló la distinción entre el contrato de obra pública y el de interventoría en lo correspondiente con la responsabilidad contractual del Estado.

\section{Consideraciones de la Sala}

En el campo de la responsabilidad contractual no basta afirmar que se incumplió una obligación dada; hay que explicar en qué consistió ese incumplimiento en la realidad y cuál fue su incidencia en la ejecución del contrato, Debe distinguirse entre el contrato de obra pública y el de interventoría, pues el incumplimiento del contratista de obra no debe imputarse al de interventoría, como si éste fuera obligado a la ejecución de la obra pública (M.P. Betancur, EXP1991-N5127).

\section{Crítica y conclusión}

Allí podemos ver el grado de diferenciación entre estas tipologías contractuales (contrato de obra e interventoría), en cuanto a que el juez contencioso hace la claridad de que el interventor no está obligado a la ejecución de la obra pública, y que las obligaciones que se derivan pueden establecer la competencia y el grado de responsabilidad de cada uno de los contratos.

La diferencia radica que el incumplimiento del contrato de obra, se materializa en la no ejecución de la misma, de lo que se ha comprometido a hacer o no hacer; en cambio en el 
de interventoría, se le exige una responsabilidad a la firma interventora para hacer efectivo el cumplimiento del control y supervisión del contratista de la obra. Esta última no va a responder sobre aspectos que tengan que ver con la realización de la obra sino con la supervisión de la misma.

\begin{tabular}{|l|l|}
\hline Institución & Consejo de Estado \\
\hline No. Expediente & $1995-N 3142$ \\
\hline Sala & Sección Primera \\
\hline
\end{tabular}

\section{Problema Jurídico}

Siguiendo con el análisis, nos encontramos con una sentencia del 24 de febrero de 1995 , donde el magistrado ponente Dr. Ernesto Rafael Ariza Muñoz, respecto del control de la interventoría.

\section{Consideraciones de la Sala}

En cuanto a la actividad de interventoría, si bien es cierto que ella está íntimamente ligada a la de la construcción, como quiera que tiene por objeto supervisar o vigilar que la obra se construya de conformidad con lo estipulado en el contrato, no lo es menos que el interventor no es quien ejecuta la obra y ello de suyo descarta la existencia de un mismo riesgo. Estando demostrado que la actividad principal de la demandante no es la de la construcción y que la consultoría e interventoría no implican el mismo riesgo de aquélla, forzoso es concluir que los actos acusados infringieron los artículos 24 del Acuerdo No. 169 de 1964 y 51 del Acuerdo No. 155 de 1963, al reclasificar a la actora en una clase de riesgo, sin tener en cuenta su actividad principal o predominante.

\section{Crítica y conclusión}

De lo anterior, se concluye que la interventoría, se mantiene indemne frente al análisis y amparo de los riesgos que con ocasión de la obra es garante la compañía aseguradora, pues la labor de la interventoría consiste en supervisar la obra, más no ejecutarla. Decisión comprensible por parte de la aseguradora puesto que no es lo mismo supervisar que ejecutar, haciendo de estas dos actividades (obra e interventoría), riesgos totalmente diferentes. 


\begin{tabular}{|l|l|}
\hline Institución & Consejo de Estado \\
\hline No. Expediente & $1998-199$ \\
\hline Sala & $\begin{array}{l}\text { Sala de Consulta y Servicio } \\
\text { Civil }\end{array}$ \\
\hline
\end{tabular}

\section{Problema Jurídico}

Continuando con el recorrido, en sentencia con ponencia del Consejero doctor Jaime Paredes Tamayo (1998), se resolvió la consulta hecha por el Ministro de Justicia de la época a cerca de los honorarios que debe ganar un interventor teniendo en cuenta el decreto número 3154 de 1980.

\section{Consideraciones de la sala}

Para este cuestionamiento, la Honorable Sala precisó:

Para construcciones por administración delegada, precios unitarios o precio alzado, 2.5\% del costo real de la obra; Cuando se trate de planes masivos de vivienda popular acometido por entidades oficiales como el Instituto de Crédito Territorial, se reducirán las tarifas en un $20 \%$.

Los honorarios por interventoría se pagarán durante la construcción, proporcionalmente a las inversiones hechas por el constructor, según los extractos de la obra.

Además, se hizo una interpretación del artículo 28, inciso $1^{\circ}$ del Decreto 3154 de 1980 y señaló:

Los honorarios por el servicio de interventoría se liquidan sobre el costo real de la obra. Se entiende por costo real de la obra para este efecto, todos los gastos que demande la construcción hasta su terminación completa, incluyendo el valor de los equipos necesarios para el funcionamiento de la edificación. Tales como: Los ascensores, ventiladores, enfriadores, unidades condensadoras, calderas, bombas, subestaciones, pantallería fija, tableros eléctricos, distribuidores telefónicos, generadores, tanques de almacenamiento, equipos contra incendio, equipos de seguridad, bóvedas, puertas de seguridad, ductos, incineradores, compactadores de basura, etc. 
Más adelante se pronunció sobre los costos que no se constituyen como honorarios del interventor; así:

No se tendrá en cuenta, dentro del costo de la construcción, para efectos del cálculo de honorarios de interventoría, el valor del terreno, el valor de gastos rembolsados de interventoría, los propios honorarios de interventoría y los honorarios correspondientes al anteproyecto, proyecto y supervisión arquitectónica, planos de estudios de ingeniería, presupuesto y programación.

\begin{tabular}{|l|l|}
\hline Institución & Consejo de Estado \\
\hline No. Expediente & 2004-1549 \\
\hline Sala & $\begin{array}{l}\text { Sala de Consulta y Servicio } \\
\text { Civil }\end{array}$ \\
\hline
\end{tabular}

\section{Problema Jurídico}

Hablaremos ahora de la responsabilidad fiscal de los interventores y específicamente revisaremos el caso relacionado con el control y vigilancia sobre las regalías destinadas a una entidad territorial. En el año 2004, acaeció a lo contencioso administrativo una consulta (M.P. Susana Montes de Echeverri) por parte del Ministro de Minas y Energía por cuanto existió una controversia entre la Comisión Nacional de Regalías en liquidación y la empresa interventora Carbocol S.A.; el Señor Ministro solicitó concepto a esa Sala sobre la existencia o no de una obligación a cargo de la Comisión Nacional de Regalías para celebrar contratos de interventoría con el fin de controlar la correcta utilización de las participaciones en las regalías directas; así como sobre las condiciones de tiempo y modo en que Carbocol S.A. "en liquidación” debía efectuar la retención y el giro de los recursos.

Igualmente, se solicitó un pronunciamiento de la Sala en torno a la aplicación del artículo 25 de la Ley 756 de 2002 con el fin de establecer el momento a partir del cual Carbocol S.A. "en liquidación" debe o debería haber retenido y girado el porcentaje de las participaciones destinado a la celebración de los contratos de interventoría.

Se hicieron entonces los siguientes interrogantes: 
1. ¿Es aplicable lo dispuesto por el parágrafo $4^{\circ}$ del artículo 25 de la Ley 756 de 2002 , con efectos retroactivos desde octubre de 2000, o solamente desde el momento en el que la Comisión Nacional de Regalías informó a Carbocol S.A. "en liquidación" el cumplimiento o acaecimiento de la condición allí contemplada, es decir, septiembre de 2002 ?

2. Si el concepto llegare a ser favorable a la retroactividad del referido descuento del $1 \%$, ¿debe Carbocol "en liquidación" descontar de los giros futuros el valor de las sumas correspondientes al periodo octubre de 2000 a septiembre de 2002?, y ¿en qué proporción y en cuánto tiempo se deben hacer tales descuentos?

\section{Consideraciones de la sala:}

A los dos primeros interrogantes ésta corporación señaló:

"Era obligación de las entidades recaudadoras de las regalías haber efectuado la retención o el descuento del $1 \%$ de las mismas correspondientes a cada entidad territorial, desde el momento en que la Comisión Nacional de Regalías formuló la solicitud de descuento de dicho porcentaje con el fin poder contratar las interventorías administrativa y financiera como mecanismo para ejercer su función de control y vigilancia sobre la inversión de los recursos provenientes de las participaciones de los entes territoriales en las regalías del Estado.

$(\ldots)$

"La inobservancia o incumplimiento de esta obligación por algunas de dichas entidades recaudadoras, puede acarrearles responsabilidades de tipo disciplinario $y$, eventualmente, patrimonial, para resarcir los daños causados con su omisión en el cumplimiento de un deber legal; sin embargo, tal situación, no permite ni autoriza que ahora se haga un descuento superior al $1 \%$ de las regalías actuales para cubrir o enmendar la omisión anterior, pues, de una parte, se estaría violando la ley al efectuar un descuento en porcentaje superior a ese $1 \%$, y, de otra, como se explicó antes, tales recursos tienen destinación específica y existe un límite en el valor máximo de los contratos a celebrar, por lo cual en la actualidad no se podrían celebrar contratos que 
excedieran ese tope y que permitieran utilizar los recursos provenientes de ese mayor descuento".

Para finalizar, hubo un último interrogante:

“3. ¿Los descuentos de hasta el $1 \%$ de las regalías de que trata el parágrafo $4^{\circ}$ del artículo 25 de la Ley 756 de 2002, solamente deben afectar las regalías a ser transferidas a las entidades territoriales objeto de la vigilancia y control para las cuales se contraten las interventorías?

A éste interrogante, señaló la corporación:

"La orden de retención y giro del $1 \%$ se deberá impartir respecto de aquellos entes territoriales para los cuales se haya tomado la decisión de realizar las interventorías mencionadas; los recursos así obtenidos solamente se podrán utilizar para ejercer la vigilancia en tales entes territoriales".

\begin{tabular}{|l|l|}
\hline Institución & Consejo de Estado \\
\hline No. Expediente & $11001-03-15-000-2003-$ \\
& $0966-01(C)$ \\
\hline Sala & Sala Plena de lo \\
& Contencioso \\
& Administrativo \\
\hline
\end{tabular}

\section{Problema Jurídico}

A continuación, nos referiremos a una sentencia de la Sala Plena de lo Contencioso Administrativo (M.P. Ortiz Barbosa María Inés, 2004), en donde se presenta un conflicto de competencias entre Empresas Varias de Medellín E.S.P. y la Procuraduría General de la Nación Provincial del Valle de Aburrá. La primera, determina que la investigación de los contratistas es exclusividad de la Procuraduría y ésta a su vez estima que cuando se trata de 
aquellos, sólo conoce cuando el sujeto disciplinable es un interventor, situación que no se observa de los contratos allegados.

Según la Procuraduría Regional del Valle de Aburra, surge la necesidad por mandato del artículo 88 del C.C.A de que el Consejo de Estado dirima el conflicto de competencias.

\section{Consideraciones de la sala}

"Se procede analizar si existe el aludido conflicto y en caso afirmativo si de la documentación anexa, en especial de los contratos, se cumple la condición para que los contratistas sean sujetos de investigación disciplinaria por parte de la Procuraduría General de la Nación o si ésta corresponde a la entidad contratante".

Se allegaron documentos anexos como lo es el contrato principal de la obra a realizar contratista, contratante- y más adelante señaló esta misma corporación:

De los documentos referenciados no se advierte que la investigación involucre la actividad de los interventores, que según los contratos citados, debieron ser designados por las Empresas Varias de Medellín E.S.P. (contratante), pues se relacionan más con su ejecución que con la vigilancia sobre los mismos y en esa medida los indicios de anomalías a que alude el Jefe de la Oficina Jurídica de las Empresas Varias de Medellín E.S.P en el oficio 51818 de 18 de octubre de 2002, afectan la responsabilidad de los contratistas para los cuales existe un régimen aplicable previsto en la Ley 80 de 1993 y es éste el que debe acatarse por las Empresas Públicas de Medellín E.S.P.

Conforme con lo analizado no se advierte entonces conflicto alguno que deba dirimirse por esta Corporación, ya que como se dejó expuesto, la presunta investigación no afecta sujetos disciplinables (interventoría) y por lo demás se trata de indicios de anomalías en la ejecución del contrato y conforme a éste y a la citada Ley 80, surgen las responsabilidades que correspondan.

\section{Crítica y conclusión}


Es clara la falta de precisión de las entidades involucradas, en cuanto al límite y funciones propias de la labor del interventor, pues ésta se relaciona con la necesidad que tienen las entidades estatales de contar con una firma o persona idónea que tenga la capacidad de vigilar desde el punto de vista técnico, jurídico y financiero la ejecución de los proyectos objeto de interventoría.

\begin{tabular}{|l|l|}
\hline Institución & Consejo de Estado \\
\hline No. Expediente & $2006-15279$ \\
\hline Sala & Sección Tercera \\
\hline
\end{tabular}

\section{Problema Jurídico}

Continuando cronológicamente, analizaremos una importante jurisprudencia, con Consejera ponente Dra. María Elena Giraldo Gómez (2006), relacionada con un llamamiento que se hace a una empresa de interventoría externa, por los hechos originados como resultado de un accidente producido a causa de unas obras de construcción, de la cual es importante citar lo siguiente:

Los hechos ocurrieron en la denominada "Troncal del Café”, en jurisdicción del municipio de Titiribí Antioquia. Aduce la parte demandante que en el lugar de los sucesos existía una roca gigante que obstruía el paso de la carretera; al pasar el vehículo con las personas después accidentadas, tuvieron que esquivar esta roca, yéndose así de forma inmediata a un abismo puesto que no existía señalización alguna que los alertara del inminente peligro. Basta aclarar que ninguno de los ocupantes del vehículo sobrevivió.

Así, sus familiares deciden demandar mediante la acción extracontractual pública a la nación (Ministerio de Obras Públicas - ahora de Transporte) y al Instituto Nacional de Vías. Estos a su vez, contestaron la demanda expresando:

La obligación del Estado de proteger la vida y los bienes de las personas es una obligación de medio y no de resultado; que el Fondo Vial Nacional contaba con los servicios de PROCOPAL S. A. como contratista y de LÓPEZ ARANGO INGENIEROS LTDA., como interventores, para la rehabilitación del sector Primavera Bolombolo de la carretera Bolombolo - Remolino, contrato en el cual se previó que el 
contratista debía señalizar el sitio donde se adelantaban las obras y el interventor, por su parte, debía vigilar el cumplimiento de tal obligación. De esta manera, en el supuesto de que no hubieran existido señales de tránsito preventivas, corresponde a ellos asumir las consecuencias contractuales y legales de tal omisión.

Sobre la relación invocada se estableció que la firma PROCOPAL S. A. celebró contrato de obra pública con el Fondo Vial Nacional, de esto se destaca:

Que el contratista tenía a su cuidado la obra y desde la suscripción del acta de recibo de la vía hasta la entrega de la misma, debía señalizar y mantener el tránsito en el sector, de acuerdo con el Manual sobre dispositivos para el control de tránsito en calles y carreteras, y las Resoluciones 5246 del 2 de julio de 1985 y 8408 del 2 de octubre de 1985; y

Que el interventor tenía a su cuidado la coordinación y vigilancia de la ejecución y cumplimiento del contrato, facultado para impartir instrucciones y órdenes al contratista.

Indicó que en materia de responsabilidad civil se aplican las disposiciones del decreto ley 222 de 1983.

De esta manera, PROCOPOL S.A. llamó en Garantía a LÓPEZ ARANGO INGENIEROS LTDA., firma interventora del contrato de la obra y a la compañía de seguros SKANDIA.

Respondió la firma interventora en escrito aduciendo que si bien actuaba dentro del contrato de interventoría celebrado con el Fondo Vial Nacional y esa firma en relación con el contrato de obra para la rehabilitación de la Troncal del Café, existía la obligación de exigir la correcta aplicación de la reglamentación vigente sobre señalización temporal y definitiva, es al contratista PROCOPAL S. A. al que le asiste el deber de señalizar y mantener el tránsito del sector contratado; que PROCOPAL S. A. colocó los avisos y las señales necesarias para garantizar el normal funcionamiento de la obra; que la oportunidad para llamar en garantía caducó por cuanto desde la ocurrencia del accidente hasta el día en que se formuló el llamamiento transcurrió un término superior a 2 años y medio; y que no 
existe relación jurídica de garantía entre la sociedad PROCOPAL S. A. y el llamado, quien actuaba como interventor en el contrato pero no era parte en él.

\section{Consideraciones de la corporación}

De la siguiente manera se pronunció el Consejo de Estado al llamamiento hecho por PROCOPAL S.A para que la firma interventora respondiera solidariamente:

Basta tener en cuenta que esta sociedad no tuvo relación contractual con su llamante PROCOPAL. Dicha sociedad fue la interventora de obra que la Administración demandada celebró con PROCOPAL.

En el contrato de obra pública se le fijaron al INTERVENTOR EXTERNO, sin mencionarlo, las obligaciones de vigilancia de la obra, como ya se vio antes. Sin embargo el mismo contrato no condicionó que el contratista implementara la señalización reglamentaria a ruego del interventor. Una cosa son las obligaciones de vigilancia del interventor y otra es la obligación autónoma del contratista para satisfacer los requerimientos de la resoluciones reglamentarias de señalización. Por lo tanto la demostración de incumplimiento del interventor frente a las obligaciones de vigilancia no es causa eficiente y determinante para que PROCOPAL pueda exigir de éste una indemnización, por reembolso total o parcial, porque de una parte quien le podría exigir indemnización a aquel sería quien lo contrató y porque, se recaba, PROCOPAL debió autónomamente satisfacer las obligaciones; él no puede trasladar su culpa ni exigir indemnización del tercero que citó, porque con él no tuvo una relación contractual que lo permita.

\begin{tabular}{|l|l|}
\hline Institución & Consejo de Estado \\
\hline No. Expediente & $\begin{array}{l}25000-23-24-000-2001- \\
00310-01 .\end{array}$ \\
\hline Sala & Sección Primera \\
\hline
\end{tabular}

\section{Problema Jurídico}


Ahora nos encontramos con un fallo referido a la Responsabilidad Fiscal (como hecho determinante de falencia en el control de la actividad administrativa); proferido por el Consejo de Estado, por incumplimiento contractual. La actora (demandante) inicia un proceso de nulidad y restablecimiento del derecho contra una resolución emitida por la Contraloría General República, puesto que en ésta, se le están imputando cargos por Responsabilidad Fiscal y detrimento al patrimonio económico del Estado, ya que se suscribió un segundo contrato con el mismo objeto del primero, haciéndose éste innecesario, para así, defraudar al Estado y satisfacer sus propios intereses.

Aduce la demandante:

Que conforme con el artículo $3^{\circ}$ de la Ley 610, sólo son procesables fiscalmente los servidores públicos y las personas de derecho privado que manejen o administren recursos o fondos públicos, para los fines que en dicha norma se determinan. En los demás casos de pérdida, daño o deterioro de bienes por causas distintas al desgaste natural que sufren las cosas, únicamente procederá la acción de responsabilidad fiscal cuando el hecho tenga relación directa con el ejercicio de actos propios de la gestión fiscal por parte de los presuntos responsables.

Además, en materia de Responsabilidad Civil y Disciplinaria señala:

En los restantes eventos de pérdida, daño o deterioro de este tipo de bienes, el resarcimiento de los perjuicios causados al erario procederá como sanción accesoria a la principal que se imponga dentro de los procesos disciplinarios que se adelanten por tales conductas o como consecuencia civil derivada de la comisión de hechos punibles, según que los hechos que originaron su ocurrencia correspondan a las faltas que sobre guarda o custodia de los bienes estatales establece el Código Disciplinario Único o a los delitos tipificados en la legislación penal.

Sostiene que desde que se inició el juicio fiscal comenzaron a relacionarse supuestas irregularidades sobre la transparencia e imparcialidad exigida por la ley en el proceso precontractual, además de que por ser el contrato de interventoría accesorio al contrato principal se adujo que debía correr la misma suerte del principal, en el entendido de que si éste está revestido de irregularidades es obvio que los accesorios quedan cubiertos por 
éstas, sin detenerse a reparar aspectos propios del debido proceso en un juicio de responsabilidad fiscal.

El pronunciamiento de la defensa en torno a este problema jurídico: "Responsabilidad Fiscal-Detrimento-interventoría", consistió en:

La Contraloría General de la República anota que el proceso de responsabilidad fiscal es definido en la Ley 42 de 1993 como el conjunto de actuaciones materiales y jurídicas que adelantan las contralorías, con el fin de determinar las consecuencias que en esa materia le corresponden a los servidores públicos y a los particulares por la gerencia irregular del patrimonio estatal en todos los órdenes y niveles.

$(\ldots)$

Resulta evidente que los sujetos pasivos del proceso de responsabilidad fiscal son los servidores públicos y las personas privadas, dentro de las cuales se encuentran los contratistas que tengan competencia o poder legal para afectar con sus decisiones y/o actuaciones el patrimonio del Estado, lo que a su turno comprende el cúmulo de facultades y capacidades que van desde las funciones donde predomina el factor intelectual, hasta aquellas labores donde prevalece el factor material, siempre que las mismas estén referidas a la gestión fiscal.

El A-quo se expresó a la imputación o no de Responsabilidad Fiscal de la siguiente forma: "Al suscribirse el contrato por el cual fue declarada fiscalmente responsable la demandante se hizo incurrir al Estado en un doble gasto, causándole un detrimento patrimonial”.

\section{Consideraciones de la sala}

Para la Sala es claro que la decisión acusada fue motivada, por lo que sólo resta determinar si lo fue debidamente, esto es, si la conducta endilgada a la demandante encuadra dentro de lo que ella denomina tipicidad cierta. Pues bien, en el expediente se encuentra el Acta de Liquidación del contrato número 0249-2-97, celebrado entre Ferrovías y Asesorías Jurídicas Especializadas de Colombia, correspondiente a la última adición del primer contrato que fue objeto de interventoría por parte de la demandante 
TERESA SÁNCHEZ DE DIAZ, en el que se lee: (...). De igual manera, en el expediente también obra el Acta de Liquidación del Contrato de Interventoría 04-00210-96 celebrado entre Ferrovías y TERESA SÁNCHEZ DE DÍAZ, la cual se ejerció sobre el contrato 0249-0-95 y sus adiciones celebrados entre Ferrovías y Asesorías Jurídicas Especializadas de Colombia, y en la que se expresó lo siguiente: (...). Surge de lo anterior que la conducta de la actora encuadra dentro de lo que ella denomina tipicidad cierta y, por tanto, la declaración de responsabilidad fiscal que sobre ella recayó se encuentra ajustada a derecho, pues si en el acta de liquidación del contrato 0249-2-97, última adición del contrato 0249-2- 95 celebrado entre Ferrovías y Asesorías Jurídicas Especializadas de Colombia, que fue objeto del contrato de interventoría 040021-0-96 suscrito por aquella, se dio cumplimiento al objeto en él estipulado y el cual la demandante no discute que coincide con el del contrato 02-0269-0-97 suscrito el 5 de enero de 1998, es obvio que el contrato de interventoría 04-0010-0-98 era innecesario, circunstancia que se tradujo en un detrimento patrimonial para el Estado que bien pudo evitar la actora, no obstante lo cual ésta procedió a suscribirlo, conducta que califica la Sala como dolosa, si se tiene en cuenta el concepto que de interventor trae el Diccionario de la Real Academia Española: "2. Empleado que autoriza y fiscaliza ciertas operaciones a fin de que se hagan con legalidad".

$(\ldots)$

En consecuencia, como a la señora Teresa Sánchez se le declaró fiscalmente responsable por haber actuado como interventora en dos contratos cuyo objeto fue el mismo, lo cual ella no contradice, es indudable que tal circunstancia se tradujo en detrimento patrimonial para el erario público, con pleno conocimiento de la actora, quien en su condición de interventora del primero de los contratos suscritos debió abstenerse de suscribir un segundo contrato de interventoría, cuestión que no hizo.

\section{Sentencia Hito}

En éste último apartado, resulta claro y evidente que hubo Responsabilidad Fiscal; por ello, el Consejo de Estado termina otorgándole la razón al a-quo y confirmando la Sentencia apelada. La actora incurrió en un doble gasto innecesario el cual está en contra del erario público y que acarrea consecuencias económicas para la Nación.

\begin{tabular}{|l|l|}
\hline Institución & Consejo de Estado \\
\hline
\end{tabular}




\begin{tabular}{|l|l|}
\hline No. Expediente & $\begin{array}{l}11001-03-26-000-2008- \\
00101-00(36054) B\end{array}$ \\
\hline Sala & Sección Tercera \\
\hline
\end{tabular}

\section{Problema Jurídico}

Para finalizar con nuestra línea jurisprudencial, nos encontramos con una Sentencia del 14 de Abril de 2010, sección tercera, con Magistrado Ponente Dr. Enrique Gil Botero; allí se demanda mediante la acción pública de Nulidad algunas disposiciones legales, entre las que se encuentran las relacionadas con interventoría, tema que nos interesa analizar.

Según el actor, la norma demandada viola el inciso segundo del parágrafo del artículo 40 de la Ley 80 de 1993, al permitir la adición indiscriminada de los contratos de interventoría sin tener en consideración que el precepto legal estatuye que ningún contrato podrá adicionarse en más de un $50 \%$ de su valor inicial.

La defensa, por su parte, resguarda la legalidad del inciso 3 del artículo 73 del Decreto 2474 de 2008, en el entendimiento que no excede la previsión legal que limita la posibilidad de adición de un contrato hasta el $50 \%$ del valor inicialmente pactado. Porque, en palabras del los demandados, "de acuerdo con el artículo 40 de la Ley 80 de 1993, la adición de los contratos estatales de cualquier índole está supeditada al valor inicial y no al plazo del contrato objeto de interventoría”.

\section{Consideraciones de la Corporación}

La Sala acogerá la pretensión formulada en atención a que como ya ha sostenido la jurisprudencia de esta Corporación las expresiones utilizadas por la ley ("adicionar" y "valor inicial"), hacen referencia a la necesidad de operar modificaciones en algunos negocios jurídicos, lo cual implica una variación en el valor pactado. En este evento, se trata de obras nuevas o distintas indispensables para alcanzar la finalidad perseguida con el acuerdo de voluntades. No obstante lo anterior, la legislación vigente contempla una limitante: el valor de lo adicionado no puede sobrepasar la mitad de lo inicialmente pactado, asegurándose su actualización mediante las variaciones que presenta el salario mínimo legal mensual. La prohibición expresada por el legislador en el artículo 40 del Estatuto de contratación estatal, es una medida que no sólo busca que no se burlen los procedimientos de selección, sino que además asegura principios como la transparencia, la selección objetiva y la planeación. Llegados a este punto, se encuentra que la norma demandada tiene el alcance que el demandante le endilga, en ella se señala la posibilidad de adicionar el contrato de interventoría sin atender a ningún límite de valor, el único 
criterio que se tiene presente es la prórroga del contrato sobre el cual se realiza la inspección y vigilancia. En otras palabras, se permite una adición que no tiene en cuenta la prohibición establecida en el artículo 40 de la Ley 80 de 1993 y que podría sobrepasar en más de un $50 \%$ el valor de lo inicialmente pactado.

Este tema ya fue debatido y finalmente resuelto por el Estatuto Anticorrupción - ley 1474 de 2011, en vista de la problemática social que se estaba generando al no poder adicionar en más de un $50 \%$ de su valor inicial un contrato de interventoría, generándose el riesgo para las entidades de quedarse sin interventor en proyectos de alta envergadura que así lo ameriten, pues la limitante prevista en el parágrafo del artículo 40 de la ley 80 de 1993, así lo prescribe.

El referido Estatuto Anticorrupción, al sanear este inconveniente prevé en su artículo 85 lo siguiente: Artículo 85. Continuidad de la interventoría. Los contratos de interventoría podrán prorrogarse por el mismo plazo que se haya prorrogado el contrato objeto de vigilancia. En tal caso el valor podrá ajustarse en atención a las obligaciones del objeto de interventoría, sin que resulte aplicable lo dispuesto en el parágrafo del artículo 40 de la Ley 80 de 1993. 


\section{Control y vigilancia disciplinaria (precedente constitucional).}

“La evolución de la sanción disciplinaria Interventoria - interventoria Externa en Colombia desde el punto de vista de la Honorable Corte Constitucional".

\begin{tabular}{|l|l|}
\hline Institución & Corte Constitucional \\
\hline No. Expediente & Sentencia C-280/1996 \\
\hline Magistrado Ponente & $\begin{array}{l}\text { Alejandro Martínez } \\
\text { Caballero }\end{array}$ \\
\hline
\end{tabular}

\section{Problema Jurídico}

Respecto de la responsabilidad disciplinaria que puede recaer sobre los particulares cuando tienen relación con el Estado.

\section{Consideraciones de la Corte}

"El criterio determinante para establecer si un particular podría ser sujeto o no de la responsabilidad disciplinaria está dado por el Estado. Si de dicha relación no se implicaba una especial subordinación del particular frente a éste, no cabe la aplicación del régimen disciplinario" (Corte Constitucional. Sentencia C-280/1996).

A continuación, hizo la adopción de un criterio material -la función pública y el interés público a ella inherente-.

\begin{tabular}{|l|l|}
\hline Institución & Corte Constitucional \\
\hline No. Expediente & Sentencia C-280/1996 \\
\hline Magistrado Ponente & $\begin{array}{l}\text { Alejandro Martínez } \\
\text { Caballero }\end{array}$ \\
\hline
\end{tabular}

\section{Problema Jurídico}

En sentencia C-286 de 1996, la Corte precisó que el criterio subjetivo expresado en la sentencia primeramente señalada resultaba plenamente inaplicable para el caso de los 
servidores públicos, pero que la responsabilidad disciplinaria del particular debía determinarse a partir de un criterio material, relacionado con la función pública que le haya sido encomendada y el interés, también público, que a ella es inherente y no con la calidad o condición de particular con la que actúa.

\section{Consideraciones de la Corporación}

Ahora bien, siendo indudable que todo servidor público, por el hecho de serlo, queda sometido automáticamente a un régimen disciplinario, según los términos previstos por la Constitución y por la ley, el fundamento de su aplicación es subjetivo, pues tiene lugar con motivo y a partir de la investidura correspondiente radicada en el sujeto, en cuanto es titular genérico de las funciones públicas que su cargo implica, con total independencia de si las ha ejercido o no.

\section{$(\ldots)$}

De allí resulta que, sin desconocer la libertad de las personas en su iniciativa y en sus actividades económicas y laborales, la Constitución haya previsto formas de vinculación de los particulares a la gestión de intereses y asuntos públicos sin que en virtud de ella pierdan su condición privada.

Así lo contemplan, entre otras normas, los artículos 2, 116, 123, 131, 221 del (acto Legislativo No. 2 de 1995), 246, 267, 277-9, 318, 340 (Sala Plena. Sentencia C-015 del 23 de Enero de 1996) y 365 de la Constitución, que autorizan el ejercicio de funciones públicas por personas particulares, en ciertas situación y previos determinados requisitos que la propia carta o las leyes establecen, o que les permiten participar en actividades de gestión de esa misma índole.

Desde luego, tal ejercicio de funciones públicas no puede estar despojado de los necesarios controles ni hallarse exento de la responsabilidad que en si mismo implica.

En los señalados eventos, el fundamento de la responsabilidad del particular es material y la aplicación del régimen disciplinario objetivo, ya que ni una ni otra atienden al estado o condición de quien actúa sino a la función pública que le ha sido encomendada y al interés, también público, que a ella es inherente.

Cambia así sustancialmente la lectura del artículo 6 de la Constitución Política, que ya no admite una interpretación literal sino sistemática: a la luz del conjunto de principios y preceptos constitucionales, el particular que se halla en cualquiera de las situaciones en las que el orden jurídico lo faculta para cumplir papeles que en principio corresponderían a organismos y funcionarios estatales, no puede ser mirado de modo absoluto bajo la óptica de una responsabilidad igual a la de los demás particulares, circunscrita apenas a su condición privada, ya que por razón de la tarea que efectivamente desarrolla, en la medida de esta y en cuanto toca con el interés colectivo, es públicamente responsable por su actividad, sin que llegue por eso a convertirse -se repite- en servidor del Estado desde el punto de vista subjetivo. 
$(\ldots)$

Con arreglo al principio de legalidad, que surge claramente para los particulares del artículo 6 de la constitución, y según el postulado del debido proceso, cuya vigencia estricta en los proceso disciplinarios ha proclamado la doctrina constitucional, la incorporación de los particulares que ejercen funciones públicas como sujetos posibles del poder disciplinario y a la expectativa de posibles procesos y sanciones ajenos a reglas legales predeterminadas o al derecho de defensa.

\begin{tabular}{|l|l|}
\hline Institución & Corte Constitucional \\
\hline No. Expediente & Sentencia C-181/02 \\
\hline Magistrado Ponente & $\begin{array}{l}\text { Marco Gerardo Monroy } \\
\text { Cabra). }\end{array}$ \\
\hline
\end{tabular}

\section{Problema Jurídico}

En sentencia posterior en el año de 1998, la Corte reitera el criterio material para determinar la responsabilidad de los particulares que ejercen funciones públicas.

\section{Consideraciones de la Corte Constitucional}

(...) Cuando se asigna al particular el cumplimiento de una función pública, éste adquiere la condición de un sujeto cualificado, en la medida en que se amplifica su capacidad jurídica, sin que por ello deje de ser un particular. Sin embargo, en este evento su situación jurídica se ve afectada en virtud de las responsabilidad que son ajenas a quien cumple funciones de la indicada naturaleza.

\section{$(\ldots)$}

En consecuencia, cuando el particular es titular de funciones públicas, correlativamente asume las consiguientes responsabilidades públicas, con todas las consecuencias que ella conlleva, en los aspectos civiles y penales, e incluso disciplinarios, según lo disponga el legislador (Sentencia C-181/02, del 12 de Marzo de 2002. M.P. Marco Gerardo Monroy Cabra).

La corte reitera en los siguientes términos el criterio de materialidad: 
Aunque, en principio, los particulares no se encuentran sometidos al régimen disciplinario de la ley 200 de 1995, pues este ha sido previsto para la sanción de las conductas desplegadas por los servidores públicos, aquellos si lo están cuando han sido encargados de la prestación de una función pública. Ello no quiere significar, según la última apreciación, que el régimen aplicable a los particulares sea, in totto, el mismo de los servidores públicos. La Ley, en cada caso, determinara cuales son los aspectos sancionatorios previstos para unos y otros, tal como se deduce el texto del inciso tercero del artículo 123 Constitucional (Sentencia C-181/02, del 12 de Marzo de 2002. M.P. Marco Gerardo Monroy Cabra).

Actualmente el criterio jurisprudencial, se constituye como un referente obligado para determinar si un particular puede ser sujeto o no de control disciplinario, amén de lo previsto en el artículo 53 del Código Disciplinario Único, donde establece:

"Artículo 53. Sujetos disciplinables. El presente régimen se aplica a los particulares que cumplan labores de interventoría en los contratos estatales; que ejerzan funciones públicas, en lo que tienen que ver con éstas; presten servicios públicos a cargo del Estado, de los contemplados en el artículo 366 de la Constitución Política o a administren recursos de éste, salvo las empresas de economía mixta que se rijan por el régimen privado. Cando se trate de personas jurídicas la responsabilidad disciplinaria será exigible del representante legal o de los miembros de la Junta Directiva".

Haciendo una lectura sistemática de la Constitución, llegamos a la conclusión de que el control disciplinario fue reservado por el constituyente para quienes cumplen de manera permanente o transitoria funciones públicas.

Podemos ver que mediante el contrato de interventoría la entidad estatal contratante traslada (mediante la delegación), facultades que le son propias, lo cual implica el ejercicio de funciones públicas.

Para fundamentar lo anterior, es del caso reiterar el contenido de algunas de las disposiciones legales que sobre el tema contempla el Estatuto General de Contratación Pública, así:

- Art 4. De los Derechos y Deberes de las Entidades Estatales. Para la consecución de los fines de que trata el artículo anterior, las entidades estatales:

1o. Exigirán del contratista la ejecución idónea y oportuna del objeto contratado. Igual exigencia podrán hacer al garante.

- $\quad$ Art 26. Del Principio de Responsabilidad. En virtud de este principio:

1o. Los servidores públicos están obligados a buscar el cumplimiento de los fines de la contratación, a vigilar la correcta ejecución del objeto contratado y a proteger los 
derechos de la entidad, del contratista y de los terceros que puedan verse afectados por la ejecución del contrato.

- Por último, el artículo 32 del mismo estatuto, faculta al interventor para emitir órdenes al contratista, enmarcadas dentro del objeto y marco del contrato vigilado.

\begin{tabular}{|l|l|}
\hline Institución & Corte Constitucional \\
\hline No. Expediente & Sentencia C-037/03 \\
\hline Magistrado Ponente & $\begin{array}{l}\text { M.P. Álvaro Tafur Charry } \\
\text { Galvis }\end{array}$ \\
\hline
\end{tabular}

\section{Problema Jurídico}

También resulta importante resaltar que la ley no establece ningún tipo de diferencia entre las funciones y responsabilidades que cumple un interventor por razón del tipo de vinculación con la entidad para la cual ejerce esta actividad.

A lo anterior, afirma la $\mathrm{H}$. Corte Constitucional:

\section{Consideraciones}

Dicha función de control, que las normas contractuales asignan a los servidores públicos, pero que excepcionalmente en virtud del contrato de interventoría puede ser ejercida por un particular, implica en realidad el ejercicio de una función pública.

$(\ldots)$

Por tratarse de un particular, precisamente, como ya se señalo, sólo en el caso de que se le atribuyan prerrogativas que puedan considerarse el ejercicio de funciones públicas cabe someter dicho particular a la ley disciplinaria (Sentencia C-037/03, del 28 de Enero de 2003. M.P. Álvaro Tafur Charry Galvis).

Esta corporación complementa su anterior consideración con el análisis de las funciones y facultades del interventor y al respecto expresa:

Téngase en cuenta que el interventor, como encargado de vigilar la buena marcha del contrato, podrá exigir al contratista la información que estime necesaria; efectuará a nombre de la administración las revisiones periódicas indispensables para verificar que las obras ejecutadas, los servicios prestados o los bienes suministrados cumplan con las condiciones de calidad ofrecida por los contratistas; podrá dar órdenes que se consignaran necesariamente por escrito; de su actuación dependerá que la administración responsable del contrato de que se trate adopte oportunamente las medidas necesarias para mantener durante su desarrollo y ejecución las condiciones técnicas, económicas y financieras que fueron previstas en él, es decir que tiene atribuidas prerrogativas de aquellas que en principio sólo corresponden a la Administración, al tiempo que su función se convierte en determinante para el cumplimiento de los fines de la contratación estatal. (Ibídem. Sentencia C-037/03, del 28 de Enero de 2003. M.P. Álvaro Tafur Charry Galvis).

\subsection{Giro jurisprudencial, conclusión.}


Además de lo expuesto anteriormente, a lo largo del precedente Constitucional, es notable el giro que dio esta honorable corporación en relación con la responsabilidad disciplinaria de los particulares que temporalmente ejercen funciones públicas y para este caso los interventores, podemos concluir que las labores de la interventoría desarrolladas en cumplimiento de contratos estatales implican que este contratista ejerza una función pública y que, en tal sentido, le es aplicable la ley disciplinaria y no únicamente la responsabilidad civil.

\section{Investigación de campo.}

Para complementar el trabajo de grado se realizó una investigación, en la cual se empleó un método mixto (cualitativo y cuantitativo) para identificar las falencias en el control de los interventores externos de la Secretaría General de la Alcaldía mayor de Bogotá, para lo cual se desarrolló un cuestionario con preguntas dirigidas a servidores públicos de esa entidad.

Se procedió a elaborar un cuestionario con las preguntas de formulación fija y flexible, de fácil, comprensión y respuesta. La recolección de fuente primaria se efectuó con los funcionarios en sus puestos de trabajo.

Se trata de un cuestionario con preguntas abiertas, esto se hizo con el fin de no sesgar las respuestas a información previamente suministrada, y con el ánimo de conocer en profundidad las falencias en el control administrativo por parte de los interventores externos en la Secretaría Mayor de la Alcaldía Mayor de Bogotá. El cuestionario se aplicó a servidores que manejan el tema a diario y que por ende tienen el conocimiento, la 
experiencia y la capacidad necesaria para ofrecer respuestas de un importante contenido para el desarrollo de esta investigación.

A continuación se procede a presentar cada pregunta y las respuestas obtenidas en la investigación de campo, y finalmente se hace un análisis e interpretación de resultados de carácter general.

Tabla N.1

\begin{tabular}{|l|c|c|}
\hline $\begin{array}{l}\text { 1. ¿En los procesos de interventoría externa se han presentado casos } \\
\text { de cuentas de cobro "infladas" en donde la entidad contratante no se } \\
\text { haya pronunciado? }\end{array}$ & SI & NO \\
\hline & & $100 \%$ \\
\hline & & \\
\hline
\end{tabular}

Fuente: elaboración propia con base a datos obtenidos en la investigación de campo realizada en la Secretaría General de la Alcaldía Mayor de Bogotá D.C.. Octubre 2011

\section{Gráfica N.1}

Fuente: elaboración propia con base a datos obtenidos en la investigación de campo realizada en

la Secretaría General de la Alcaldía Mayor de Bogotá D.C.. Octubre 
En lo concerniente con la primera pregunta, los funcionarios de la Secretaria General de la Alcaldía Mayor de Bogotá, manifiestan que no se han presentado cuentas "infladas" porque son debidamente auditadas y hay cláusulas que regulan el incumplimiento de las obligaciones contractuales. No se han detectado anomalías porque hay supervisores encargados de coordinar los trámites ordinarios. Otros manifiestan no tener conocimiento al respecto.

Tabla N.2

\begin{tabular}{|l|c|c|}
\hline $\begin{array}{l}\text { 2. Se ha presentado el caso de aumentos de salario dentro de un } \\
\text { mismo contrato y la entidad contratante no haya presentado } \\
\text { objeciones? }\end{array}$ & SI & NO \\
\hline & $37,50 \%$ & $62,50 \%$ \\
\hline Por favor explique & & \\
\hline
\end{tabular}

Fuente: elaboración propia con base a datos obtenidos en la investigación de campo realizada en la Secretaría General de la Alcaldía Mayor de Bogotá D.C.. Octubre 2011

\section{Gráfica N.2}

Fuente: elaboración propia con base a datos obtenidos en la investigación de campo realizada en la Secretaría

General de la Alcaldía Mayor de Bogotá D.C.. Octubre 2011

En lo referente a la segunda pregunta, un $37.5 \%$ manifiesta que si se han presentado aumentos de salarios dentro de un mismo contrato con ocasión de una nueva obligación contractual pero que está plenamente justificado. Un 62.5\% manifiesta que no conocen trámites al respecto, por lo tanto no han existido pronunciamientos en ese sentido. Algunos afirman que se presenta en contratos de aseo y cafetería. Otros afirman que se presenta por cambio de año por los ajustes que se deben efectuar. 


\section{Tabla N.3}

\begin{tabular}{|l|c|c|}
\hline $\begin{array}{l}\text { 3. ¿Se ha presentado falta de seguimiento por parte de la } \\
\text { entidad contratante sobre los contratos que han sido encargados a } \\
\text { los interventores externos? }\end{array}$ & SI & NO \\
\hline & & $100 \%$ \\
\hline & & \\
Por favor explique
\end{tabular}

Fuente: elaboración propia con base a datos obtenidos en la investigación de campo realizada en la Secretaría General de la Alcaldía Mayor de Bogotá D.C.. Octubre 2011

\section{Gráfica N.3}

Fuente: elaboración propia con base a datos obtenidos en la investigación de campo realizada en la Secretaría

General de la Alcaldçia Mayor de Bogotá D.C.. Octubre 2011

En cuanto a la pregunta, si, se ha presentado falta de seguimiento por parte de la entidad contratante sobre los contratos que hayan sido encargados a los interventores externos, el $100 \%$ de los encuestados manifestó categóricamente que no. Lo cual demuestra eficiencia en ese sentido.

Tabla N.4

\begin{tabular}{|l|c|c|}
\hline $\begin{array}{l}\text { 4. Se han detectado interventorías externas con pocos informes } \\
\text { sobre los avances en los contratos sin que el funcionario competente } \\
\text { de la entidad contratante no haya puesto ningún reparo? }\end{array}$ & SI & NO \\
\hline & $12,50 \%$ & $87,50 \%$ \\
\hline & & \\
\hline
\end{tabular}


Fuente: elaboración propia con base a datos obtenidos en la investigación de campo realizada en la Secretaría General de la Alcaldía Mayor de Bogotá D.C.. Octubre 2011

\section{Gráfica N.4}

Fuente: elaboración propia con base a datos obtenidos en la investigación de campo realizada en la Secretaría

General de la Alcaldía Mayor de Bogotá D.C.. Octubre 2011

Un $87.5 \%$, frente a la anterior pregunta considera que la entidad cuenta con mecanismos de seguimiento que permiten controlar la ejecución contractual. La supervisión, control y vigilancia de la ejecución del respectivo contrato, la ejerce el supervisor o coordinador técnico administrativo, quien hace los requerimientos. En cuanto al $12.5 \%$ restante de los encuestados manifiestan que se presentan fallas por la excesiva rotación y falta de capacitación por parte de la entidad contratante.

\section{Tabla N.5}

\begin{tabular}{|l|c|c|}
\hline $\begin{array}{l}5, \text { ¿Se ha presentado laxitud por parte de la entidad contratante } \\
\text { frente a los interventores en materia de calidad y cumplimiento de } \\
\text { sus obligaciones? }\end{array}$ & SI & NO \\
\hline & & $100 \%$ \\
\hline
\end{tabular}

Fuente: elaboración propia con base a datos obtenidos en la investigación de campo realizada en la Secretaría General de la Alcaldía Mayor de Bogotá D.C.. Octubre 2011

\section{Gráfica N.5}


Fuente: elaboración propia con base a datos obtenidos en la investigación de campo realizada en la Secretaría

General de la Alcaldía Mayor de Bogotá D.C.. Octubre 2011

El $100 \%$ de los encuestados manifiesta que no se ha presentado laxitud por parte de la entidad contratante, además que los interventores son requeridos para que cumplan con su deber y que excepcionalmente se han presentado llamados de atención a las obligaciones del interventor pero que son corregidas y atendidas con la debida justificación soportada legal y contractualmente.

Tabla N.6

\begin{tabular}{|l|c|c|}
\hline $\begin{array}{l}\text { 6. ¿Se ha dado el caso en el que un interventor sea contratado } \\
\text { tardíamente para que supervise una obra? }\end{array}$ & SI & NO \\
\hline & & $100 \%$ \\
\hline Por favor explique
\end{tabular}

Fuente: elaboración propia con base a datos obtenidos en la investigación de campo realizada en la Secretaría General de la Alcaldía Mayor de Bogotá D.C.. Octubre 2011

\section{Gráfica N.6}

Fuente: elaboración propia con base a datos obtenidos en la investigación de campo realizada en la Secretaría

General de la Alcaldía Mayor de Bogotá D.C.. Octubre 2011

Frente a esta pregunta, no se ha dado el caso en el que un interventor se contrate tardíamente para supervisar una obra, pues el $100 \%$ de los encuestados manifestó que no se ha presentado este fenómeno. 
Tabla N.7 


\begin{tabular}{|l|c|c|}
\hline $\begin{array}{l}\text { 7. ¿Se ha presentado el caso en el que un interventor externo no } \\
\text { haya iniciado el proceso de multa contra el contratista por atrasos } \\
\text { y la entidad contratante no haya señalado nada al respecto?. }\end{array}$ & SI & NO \\
\hline & & $100 \%$ \\
\hline
\end{tabular}

Fuente: elaboración propia con base a datos obtenidos en la investigación de campo realizada en la Secretaría General de la Alcaldía Mayor de Bogotá D.C.. Octubre 2011

\section{Gráfica N.7}

Fuente: elaboración propia con base a datos obtenidos en la investigación de campo realizada en la Secretaría

General de la Alcaldía Mayor de Bogotá D.C.. Octubre 2011

El $100 \%$ de los encuestados manifestó que no se ha dado el caso o que por lo menos no tienen conocimiento al respecto, y que por el contrario los procedimientos sancionatorios se inician gracias a la labor desarrollada por el Interventor del contrato.

\section{Tabla N.8}

\begin{tabular}{|l|c|c|}
\hline $\begin{array}{l}\text { 8. ¿Influye de alguna manera el proceso de contratación de } \\
\text { interventores externos en el presupuesto de la entidad contratante? }\end{array}$ & SI & NO \\
\hline & $37,50 \%$ & $62,50 \%$ \\
\hline & & \\
\hline
\end{tabular}

Fuente: elaboración propia con base a datos obtenidos en la investigación de campo realizada en la Secretaría General de la Alcaldía Mayor de Bogotá D.C.. Octubre 2011

\section{Gráfica N.8}


Fuente: elaboración propia con base a datos obtenidos en la investigación de campo realizada en la Secretaría

General de la Alcaldía Mayor de Bogotá D.C.. Octubre 2011

Un $37.5 \%$ de los encuestados manifiesta que si porque todo proceso de selección y suscripción conlleva afectación en el presupuesto de la entidad para soportar la ejecución del contrato ya que debe establecerse el compromiso presupuestal correspondiente. El $62.5 \%$ manifestó que no porque la entidad utiliza muy poco la figura de la interventoría externa y por ende no se afecta sustancialmente el presupuesto de la entidad.

Tabla N.9

\begin{tabular}{|l|c|c|}
\hline $\begin{array}{l}\text { 9. ¿Se ha presentado el caso en el que el interventor externo } \\
\text { ignore las sugerencias que le hace la comunidad o el ente } \\
\text { contratante? }\end{array}$ & SI & NO \\
\hline & & $100 \%$ \\
\hline Por favor explique
\end{tabular}

Fuente: elaboración propia con base a datos obtenidos en la investigación de campo realizada en la Secretaría General de la Alcaldía Mayor de Bogotá D.C.. Octubre 2011

Gráfica N.9

Fuente: elaboración propia con base a datos obtenidos en la investigación de campo realizada en la Secretaría

General de la Alcaldía Mayor de Bogotá D.C.. Octubre 2011

El $100 \%$ de los encuestados manifiesta que no, porque los interventores son respetuosos respecto de las sugerencias que son realizadas por el funcionario competente de la entidad 
y cumplen sus obligaciones contractuales. En cuanto a la comunidad, los encuestados no tienen conocimiento del reporte de algún tipo de anomalía.

Tabla N.10

\begin{tabular}{|l|c|c|}
\hline $\begin{array}{l}10 . \quad ¿ \text { Se han recibido obras a satisfacción por parte del } \\
\text { interventor sin cumplir con los requerimientos exigidos donde la } \\
\text { entidad contratante no se ha pronunciado? }\end{array}$ & SI & NO \\
\hline & & $100 \%$ \\
\hline Por favor explique & \\
\hline
\end{tabular}

Fuente: elaboración propia con base a datos obtenidos en la investigación de campo realizada en la Secretaría General de la Alcaldía Mayor de Bogotá D.C.. Octubre 2011

Gráfica N.10

Fuente: elaboración propia con base a datos obtenidos en la investigación de campo realizada en la Secretaría

General de la Alcaldía Mayor de Bogotá D.C.. Octubre 2011

El $100 \%$ de manifestó que no, porque la entidad no recibe obras sin el lleno de los requisitos y especificaciones exigidas, y en el evento de presentarse una situación de tal naturaleza adopta las medidas y acciones necesarias para declarar el incumplimiento de las obligaciones contractuales.

\section{Tabla N.11}

\begin{tabular}{|l|c|c|}
\hline $\begin{array}{l}\text { 11. ¿La forma de contratación de interventores externos se hace } \\
\text { aplicando procedimientos legales de contratación o son nombrados a } \\
\text { "dedo" por el funcionario competente de la entidad contratante? }\end{array}$ & SI & NO \\
\hline & & $100 \%$ \\
\hline & & \\
\hline
\end{tabular}


Fuente: elaboración propia con base a datos obtenidos en la investigación de campo realizada en la Secretaría General de la Alcaldçia Mayor de Bogotá D.C.. Octubre 2011

\section{Gráfica N.11}

Fuente: elaboración propia con base a datos obtenidos en la investigación de campo realizada en la Secretaría

General de la Alcaldía Mayor de Bogotá D.C.. Octubre 2011

En esta última pregunta el $100 \%$ manifiesta que los nombramientos no son realizados a "dedo" porque se hace mediante un proceso de selección objetiva y concurso de méritos de acuerdo con la normatividad legal vigente.

\section{CONCLUSIONES Y RECOMENDACIONES}

En la secretaria General de la Alcaldía Mayor de Bogotá al parecer hay una adecuada auditoría en el manejo de las cuentas en lo referente a la interventoría externa.

Se interpreta que hay un debido seguimiento a los contratos encargados a los interventores externos, porque son pocas las obras civiles que se realizan.

Hay evidencia de excesiva rotación de los supervisores internos, lo que es contraproducente por el alto volumen de obligaciones y funciones a cargo de los servidores públicos que adicionalmente a las labores de control y vigilancia que les son asignadas, tienen que estar 
al tanto de sus funciones normales en cada una de las dependencias en las que prestan sus servicios.

En la Secretaría General de la Alcaldía Mayor de Bogotá, no se evidencia falta de control por parte de los interventores externos y de los supervisores, toda vez que existe un buen nivel de capacitación sobre la normatividad aplicable en materia de control y vigilancia contractual, y porque igualmente existen Manuales de contratación vigentes que son concordantes con la normatividad legal vigente.

De acuerdo con lo anterior, es claro que en la medida en que las entidades estatales cuenten con personal calificado e idóneo encargado de efectuar las correspondientes supervisiones a los contratos, que adicionalmente tengan como prioritaria la capacitación y adopción de manuales de contratación, se disminuye notablemente la falta de control y las consecuentes falencias en el control administrativo que conllevan a sanciones por detrimento patrimonial, reclamaciones por desequilibrio económico, incumplimiento de las obligaciones especialmente en los cronogramas, amortización de anticipos, etc.

Hay que Explorar la posibilidad de redactar un proyecto normativo al interior de cada entidad, para que el funcionario encargado de ejercer la supervisión interna cuente con mecanismos y herramientas que garanticen el adecuado control de la ejecución contractual.

No se debe sobrecargar laboralmente a los supervisores internos, porque esto genera un inadecuado control y vigilancia, presentándose un desgaste humano que se ve reflejado en el ejercicio de una labor poco eficiente.

Se sugiere que la Secretaría General de la Alcaldía Mayor de Bogotá y demás entidades adopten en su sistema de gestión de calidad, la evaluación permanente de los interventores externos así como los supervisores internos.

Se requiere capacitar al personal de contratación en las labores propias del desarrollo de sus funciones, lo cual se verá reflejado en una labor eficiente y responsable del interventor externo. 
Quienes ejerzan la supervisión y el control de los interventores externos en la Secretaría General de la Alcaldía Mayor de Bogotá, deben exigir a los contratistas, la totalidad de documentos y soportes que den cuenta del cumplimiento de sus obligaciones contractuales, para evitar traumatismos en el procedimiento de liquidación de los contratos. 


\section{BIBLIOGRAFIA}

\section{- DOCTRINAL}

1. Aguilar Cartagena, María Victoria y otro (2000). Funciones del residente de obra en construcciones de pequeña y mediana complejidad. Facultad de arquitectura. Medellín.

2. Bautista, M. Á. (1996). La interventoría y el control integral, Bogotá, Cargrafics. S.A., 1998, p. 71.

3. Cardona Gutiérrez, Diana M. (2004) . El papel de la interventoría en la empresa L $C$ A rango Arango S.A. Trabajo de grado universidad Nacional de Colombia. Medellín.

4. Del Castillo Freite Juvenal. (1979) Manual de Procedimientos de la interventoría. Ministerio de salud pública.

5. ERIKSSON, Per Erik. Procurement effects on coopetition in client-contractor relationships. Journal of Construction Engineering and Management, Vol. 134, No. 2., Luleå, University of Technology, February 2008, pp. 103-111.

6. F. Cepeda, Fedesarrollo. (1997).Causas de la corrupción La corrupción en Colombia, Bogotá, Tercer Mundo.

7. Gaitan Lemoine Jaime. (2010). Responsabilidad del interventor. Universidad nacional, facultad de Ciencias Económicas, Centro de investigación para el desarrollo (CID). Editorial Universidad Nacional de Colombia.

8. Gorbaneff Yuri; González Juan Manuel; Barón( Leonardo (2011) . ¿Para Qué Sirve La Interventoría De Las Obras Públicas En Colombia?. Revista de Economía Institucional, vol. 13, n. ${ }^{\circ}$ 24, primer semestre /2011, pp. 413-428.

9. Jiménez, M. (2007) .Interventoría de proyectos públicos, Bogotá, Universidad Nacional de Colombia.

10. García Marín, Claudia Andrea; Aguirre Torres, Ruby Lucia, Millán Mejía, Juan Alejandro (2010). Las interventorías para ejercer supervisión, coordinación y control dentro de los procesos de contratación estatal. Pereira. Universidad libre.

11. Gómez De Vargas Inés (2001). Rol de la Interventoria en Los Contratos y Convenios que Celebren las entidades Territoriales Para Garantizar la Atención en Salud. Superintendente Nacional de Salud Bogotá.

12. Lemoine Gaitán, Jaime. Responsabilidad del interventor (2010). 
13. Londoño Escobar, Jaime H. (1994). La interventoría moderna. Ingeniería estructural Ltda. Medellín.

14. López Valencia, Felipe A.(2005). Responsabilidades normativas, servicios y funciones de la interventoría en Colombia. Facultad de Arquitectura. Medellín.

15. Marín Gaviria María Eugenia, Vélez Blandón Luis Guillermo, Morales Londoño Marcela, Martínez Moreno Oscar Enrique (2010). Guía práctica para el manejo e interventoría de obras civiles bajo el esquema de control de calidad. Cornare. Universidad de Medellín.

16. Parra Parra, José E. (2002) El contrato de interventoría . Ediciones Jurídicas Gustavo Ibáñez.

17. Peláez Rodríguez, Andrés y otro (2001) . Interventoría de edificaciones complejas privadas bajo diferentes sistemas de contratación. Universidad Nacional de Colombia: Medellín.

18. Posada Cuartas, Claudia H. (1997). La interventoría de una obra contratada por Administración Delegada en el sector privado. Universidad Nacional de Colombia. Medellín.

19. Puerta Luis E. y otro. (1999). Controles técnicos administrativos y jurídicos a cargo del interventor para la gestión ambiental de una obra de construcción. Universidad Nacional de Colombia. Medellín.

20. Puyana Germàn, y otro. (1983) Interventoría de edificios. Camacol. Medellín.

21. Quintero, Victor Manuel. (2002) Interventoría técnica a proyectos sociales. Revista Gestión y desarrollo. Universidad de San Buenaventura-Cali. Edición No 9.

22. Restrepo Aristizabal, Claudia M. (1999) sistema de manejo de información para la interventoría de proyectos de construcción. Universidad Nacional de Colombia. Medellín.

23. Sánchez Henao, Julio C. (2001). Especialización en interventoría de proyectos. Universidad nacional de Colombia. Medellín.

24. Solano Arroyo, Álvaro M. 2005). La interventoría en obras edilicas y civiles bajo diferentes modalidades de contratación en Colombia. Universidad Nacional de Colombia. Medellín.

25. Torres Guerra, William (2001). Líneas de profundización en interventoría de proyectos de obras. Universidad Nacional de Colombia. Medellín.

26. Vargas Cantor, Edgar F (2003). Interventoría de obras públicas. Conceptualización y procedimentalización. Ediciones jurídicas Gustavo Ibáñez. 
27. Vidal Vanegas, Heriberto. (2002) Interventoría de edificaciones para arquitectos, ingenieros constructores y tecnólogos. Medellín.

28. Urdaneta Hernández Germán (1998). Interventoría de la obra pública. Centro Editorial Javeriano.

- DOCUMENTAL

29. Alcaldía de Medellín. Manual práctico de interventoría (2000). Municipio de Medellín : secretaria Jurídica.

30. Alcaldía de Medellín. Manual práctico de interventoría (2000). Municipio de Medellín : secretaria Jurídica.

31. Contrato de interventoria, técnica, administrativa y financiera del contrato de obra pública (2011). Corporación autónoma regional de la Guajira.

32. Interventoria de obras de infraestructura energética (2009). Genza.

33. Interventoria técnica y administrativa para la construcción de obras civiles de recreación.(2009). Alcaldía de Armenia.

34. La interventoría en Colombia: un aspecto de reflexión académica. Escrito por Cesar Prieto, Carlos Rodríguez, Diana Ruiz y Viana Rubiano documentos CID.

35. Manual práctico de interventores y supervisores de los contratos estatales. Resolución 63 de 2006.

36. Manual de interventoría.(2008-2011) Alcaldía Municipal Yaguara. Huila.

37. Manual de interventoría de obras: Alcaldía de San José del Guaviare.

38. Manual de interventoría o supervisión de contratos u órdenes contractuales diferentes a contratos de obras. Universidad del Valle. http://procesos.univalle.edu.co/documentos/Manual\%2520Interventor\%25EDa.pdf.

39. Manual De Interventoría Y/O Supervisión Del Ministerio De Ambiente Vivienda Y Desarrollo Territorial, En Adelante El Ministerio Y Del Fondo Nacional Ambiental, En Adelante El Fonam.

40. Memorias Jornada de contratación. Cartagena de Indias. 2005 y 2006.

41. Ministerio de Transporte. (2001) Manual de procedimientos de interventoría y Supervisión de contratos. Bogotá. 
42. Responsabilidad de interventores y supervisores en los contratos estatales, directriz jurídica de 06 de 2006 . Bogotá marzo- 2006.

43. Univalle (2009). Manual de interventoría o supervisión de contratos u órganos contractuales diferentes de los contratos de obras.

- NORMATIVIDAD

44. Decreto 2170/ 2002. Por el cual se reglamenta la Ley 80 de 1993, se modifica el Decreto 855 de 1994 y se dictan otras disposiciones en la aplicación de la Ley 527 de 1999.

45. Circular 005/ 2002. Anuncia creación del Portal Contratación a la Vista Alcalde Mayor de Bogotá.

46. Decreto 3512/ 2003. Por el cual se reglamenta la organización, funcionamiento y operación del sistema de información para la vigilancia de la Contratación SICE, creado mediante la ley 598 de 2000.Departamento Nacional de Planeación.

47. Circular 005/2004. Publicación de la Información Contractual. Veeduría Distrital y Secretaría General Alcaldía Mayor de Bogotá.

48. Circular 027/2005. Prevención del daño antijurídico en la Contratación Fortalecimiento de la gestión Contractual Secretaría General Alcaldía Mayor de Bogotá.

49. Circular 028/2005. Instrucciones para postulación y sorteo en los procesos de contratación directa Secretaría General Alcaldía Mayor de Bogotá.

50. Circular 041/2007 Funcionamiento Portal Contratación a la Vista y Sistema Electrónico para la Contratación Pública SECOP Secretaría General Alcaldía Mayor de Bogotá.

51. Ley 1150/ 2007 Por medio de la cual se introducen medidas para la eficiencia y la transparencia en la ley 80 de 1993 y se dictan otras disposiciones generales sobre la contratación con recursos públicos. Congreso de la República.

52. Circular 005/ 2008 Portal de Contratación a la Vista-Transparencia de la Gestión Contractual. Secretaría General Alcaldía Mayor de Bogotá.

53. Decreto 4881/ 2008 Por el cual se reglamenta parcialmente la ley 1150 de 2007 en relación con la verificación de las condiciones de los proponentes y su acreditación para el Registro Único de Proponentes a Cargo de las Cámaras de Comercio y se dictan otras disposiciones. Departamento Nacional de Planeación. 
54. Exposición de motivos Ley 80 de 1993. Artículo primero del proyecto.

55. Ley 801993 Por la cual se expide el Estatuto General de Contratación de la Administración Pública.

56. Ley 734 de 2002.

57. Ley 1150 de 2007. Artículo 21.

58. Proyecto de Ley número 19 de 2000 . Artículo 61.

59. Proyecto de Ley número 142 de 2010. disposiciones para prevenir y combatir la corrupción en la contratación pública.

\section{- JURISPRUDENCIAL}

60. Corte Constitucional, Sentencia C-727/00.

61. Corte Constitucional. Sentencia C-286/96, del 27 de Junio de 1996. M.P. José Gregorio Hernández Galindo.

62. Corte Constitucional, Sentencia C-372/02. Estudio de exequibilidad del artículo 2 de la Ley 678 de 2001.

63. Corte Constitucional, Sentencia C- 693/08. Exequibilidad del artículo 21 de la Ley 1150 de 2007.

64. Corte Constitucional, Sentencia C-563 de 1998.

65. Corte Constitucional. Sentencia C-280/1996, del 25 de Junio de 1996. M.P. Alejandro Martínez Caballero.

66. Corte Constitucional. Sentencia C-181/02, del 12 de Marzo de 2002. M.P. Marco Gerardo Monroy Cabra. 
67. Consejo de Estado, Sala de lo Contencioso Administrativo, Sección tercera. EXP1991-N5127. M.P. Carlos Betancur Jaramillo. septiembre trece (13) de mil novecientos noventa y uno (1991).

68. Consejo de Estado, Sala de lo Contencioso Administrativo, Sección Primera. EXP 1995-N3142. M.P. Ernesto Rafael Ariza Muñoz. (24) de febrero de mil novecientos noventa y cinco (1995).

69. Consejo de Estado, Sala de Consulta y Servicio Civil. EXP1998-199. C.P. Dr. Jaime Paredes Tamayo.

70. Consejo de Estado, Sala de lo Contencioso Administrativo, Sección Tercera. EXP2000-17234. M.P. Carlos Manuel Polo Jiménez. treinta y uno (31) de agosto de dos mil (2000).

71. Consejo de Estado, Sala de Consulta y Servicio Civil. EXP2004-1549. M.P. Susana Montes de Echeverri.

72. Consejo de Estado, Sala Plena de lo Contencioso Administrativo (2004). EXP11001-03-15-000-2003-0966-01(C). M.P. María Inés Ortiz Barbosa.

73. Consejo de Estado, Sala de lo Contencioso Administrativo, Sección Tercera. EXP2006-15279. M.P. María Elena Giraldo Gómez.

74. Consejo de Estado, Sala de lo Contencioso Administrativo, Sección Primera. M.P. Martha Sofía Sanz Tobon. N-Radicado. 25000-23-24-000-2001-00310-01.

75. Consejo de Estado, Sala de lo Contencioso Administrativo, sección tercera. M.P. Enrique Gil Botero. N-R. 11001-03-26-000-2008-00101-00(36054) B. 


\section{ANEXO}

\section{CUESTIONARIO}

\section{FALENCIAS EN EL CONTROL ADMINISTRATIVO}

\section{DE LOS INTERVENTORES EXTERNOS}

\section{POR PARTE DE LA SECRETARÍA GENERAL}

\section{DE LA ALCALDIA MAYOR DE BOGOTA D.C}

Instrumento dirigido al personal encargado de contratación

Solicitamos su colaboración, para contestar de la manera más precisa y objetiva el siguiente cuestionario.

Objetivo: se utiliza como instrumento de recolección de información acerca de las falencias en el control de los interventores externos por parte de la entidad contratante* y los resultados que se obtengan, serán de carácter confidencial y se usaran solo con fines académicos.

Nota: no requiere colocar su nombre en el cuestionario.

*Nota. La entidad contratante es la Secretaría General de la Alcaldía Mayor de Bogotá D.C

\section{PREGUNTAS}

Se trata de una serie de preguntas en las cuales usted deberá responder marcando con una $\mathbf{X}$ en un SI o un NO y ampliando la respuesta.

1. ¿En los procesos de interventoria externa se han presentado casos de cuentas de cobro "infladas" en donde la entidad contratante no se haya pronunciado?

Por favor explique

2. Se ha presentado el caso de aumentos de salario dentro de un mismo contrato y la entidad contratante no haya presentado objeciones?

\begin{tabular}{|l|l|}
\hline & \\
\hline
\end{tabular}

Por favor explique

3. iSe ha presentado falta de seguimiento por parte de la entidad contratante sobre los contratos que han sido encargados a los interventores externos? 


\begin{tabular}{|c|c|c|}
\hline $\begin{array}{l}\text { 4. Se han detectado interventorias externas con pocos informes sobre } \\
\text { los avances en los contratos sin que el funcionario competente de la } \\
\text { entidad contratante no haya puesto ningún reparo? }\end{array}$ & SI & NO \\
\hline \multicolumn{3}{|l|}{ Por favor explique } \\
\hline $\begin{array}{l}\text { 5, ¿Se ha presentado laxitud por parte de la entidad contratante frente a } \\
\text { los interventores en mateeria de calidad y cumplimiento de sus } \\
\text { obligaciones? }\end{array}$ & SI & NO \\
\hline \multicolumn{3}{|l|}{ Por favor explique } \\
\hline $\begin{array}{l}\text { 6. ¿Se ha dado el caso en el que un interventor sea contratado } \\
\text { tardíamente para que supervise una obra? }\end{array}$ & SI & NO \\
\hline \multicolumn{3}{|l|}{ Por favor explique } \\
\hline $\begin{array}{l}\text { 7. ¿Se ha presentado el caso en el que un interventor externo no haya } \\
\text { iniciado el proceso de multa contra el contratista por atrasos y la entidad } \\
\text { contratante no haya señalado nada al respecto? }\end{array}$ & SI & NO \\
\hline \multicolumn{3}{|l|}{ Por favor explique } \\
\hline $\begin{array}{l}\text { 8. ¿Influye de alguna manera el proceso de contratación de } \\
\text { interventores externos en el presupuesto de la entidad contratante? }\end{array}$ & SI & NO \\
\hline \multicolumn{3}{|l|}{ Por favor explique } \\
\hline $\begin{array}{l}\text { 9. ¿Se ha presentado el caso en el que el interventor externo ignore las } \\
\text { sugerencias que le hace la comunidad o el ente contratante? }\end{array}$ & SI & NO \\
\hline \multicolumn{3}{|l|}{ Por favor explique } \\
\hline $\begin{array}{l}\text { 10. ¿Se han recibido obras a satisfacción por parte del interventor sin } \\
\text { cumplir con los requerimientos exigidos donde la entidad contratante no } \\
\text { se ha pronunciado? }\end{array}$ & SI & NO \\
\hline $\begin{array}{l}\text { 11. ¿La forma de contratación de interventores externos se hace } \\
\text { aplicando procedimientos legales de contratación o son nombrados a }\end{array}$ & SI & NO \\
\hline
\end{tabular}


"dedo" por el funcionario competente de la entidad contratante?

Por favor explique

Gracias por su valiosa colaboración.

Fuente: elaboración propia con base a datos obtenidos en la investigación de campo

realizada en la secretaria General de la Alcaldía mayor de Bogotá. Octubre 2011 